\title{
Conformational study and reassessment of the vibrational assignments for Norspermidine
}

\author{
T.M. Silva ${ }^{\text {a }}$, S.M. Fiuza ${ }^{\text {a }}$, M.P.M. Marques ${ }^{\text {a,b }}$, L.A.E. Batista de Carvalho ${ }^{\text {a }}$, A.M. Amado ${ }^{\text {a,* }}$ \\ a IED Unit "Química-Física Molecular”, Department of Chemistry, Faculty of Science and Technology, University of Coimbra, P-3004-535 Coimbra, Portugal \\ b Department of Life Sciences, University of Coimbra, 3000-456 Coimbra, Portugal
}

\section{A R T I C L E I N F O}

\section{Article history:}

Received 12 October 2015

Accepted 4 January 2016

Available online 8 January 2016

\section{Keywords:}

Norspermidine

Vibrational spectroscopy

Conformational preferences

Quantum chemical calculations

Dielectric constant effect

\begin{abstract}
A B S T R A C T
The present study presents and discusses the conformational preferences of Norspermidine (NSpd). The effects of varying the dielectric constant on the conformational preferences are discussed, with a view to infer which conformation will correspond to the most stable in the pure condensed liquid phase. Within the same context, a set of NSpd- $\mathrm{NH}_{3}$ molecular adducts were simulated in order to determine the relevance of intermolecular hydrogen bonding on the overall stability and relative positioning of the respective vibrational frequencies. The calculations presently performed allowed a reassessment of the vibrational assignments for NSpd. A full assignment of the NSpd vibrational spectra is presented, with special emphasis being given to the vibrational modes that proved to be most affected by hydrogen bonding. The various inconsistencies of a prior study found in the literature were identified and rectified.
\end{abstract}

(c) 2016 Elsevier B.V. All rights reserved.

\section{Introduction}

Polyamines, such as putrescine $\left[\mathrm{H}_{2} \mathrm{~N}\left(\mathrm{CH}_{2}\right)_{4} \mathrm{NH}_{2}\right.$, Put], spermidine $\left[\mathrm{H}_{2} \mathrm{~N}\left(\mathrm{CH}_{2}\right)_{3} \mathrm{NH}\left(\mathrm{CH}_{2}\right)_{4} \mathrm{NH}_{2}\right.$, Spd] and spermine $\left[\mathrm{H}_{2} \mathrm{~N}\left(\mathrm{CH}_{2}\right)_{3} \mathrm{NH}\left(\mathrm{CH}_{2}\right)_{4}\right.$ $\left.\mathrm{NH}\left(\mathrm{CH}_{2}\right)_{3} \mathrm{NH}_{2}, \mathrm{Spm}\right]$, are found in most living cells in millimolar concentrations. At physiological $\mathrm{pH}$ conditions these systems are $\mathrm{N}-$ protonated, thus behaving as intrinsic polycations. A bewildering maze of cellular functions has been ascribed to these important biogenic compounds. They were shown to be essential in eukaryotic cell growth and differentiation, as well as in the maintenance of the native structure of different biological macromolecules [1-5]. Since deregulated polyamine metabolism is recognized as a characteristic of animal cancers $[4,6-8]$, interference with the polyamine biosynthetic pathways seems to be a very promising therapeutical approach against proliferative diseases [9-11].

The accidental discovery of the antitumor properties of cisplatin (cisdiamminedichloroplatinum(II), hereafter named as cDDP; Scheme 1) by Rosenberg et al. [12-14], prompted a growing interest towards the development of new metal-based anticancer drugs. The finding led to a renewed interest in the field of polyamines, which have become potential substituent groups for the replacement of the $\mathrm{CDDP} \mathrm{NH}_{3}$ ligands in cDDP aiming at the design of new cisplatin-like anticancer drug candidates $[15,16]$.

In recent years, the authors have been interested in the understanding of the structure-activity relationships (SARs) that underline the

\footnotetext{
* Corresponding author.

E-mail address: amado.am@gmail.com (A.M. Amado).
}

antineoplastic activity of some platinum(II) and palladium(II) complexes with linear alkylpolyamines. The structural characterization of both polyamine ligands and metal complexes has been mainly performed by vibrational spectroscopy (Raman, inelastic neutron scattering (INS) and infrared) coupled to quantum chemical calculations [17-30]. One of the polyamines that has been considered is norspermidine (bis(3-aminopropyl)amine, $\mathrm{H}_{2} \mathrm{~N}\left(\mathrm{CH}_{2}\right)_{3} \mathrm{NH}\left(\mathrm{CH}_{2}\right)_{3} \mathrm{NH}_{2}$, NSpd; Scheme 2), a modified polyamine structurally related to the biogenic polyamine spermidine ( $\mathrm{N}$-(3-aminopropyl)-1,4-butanediamine), Spd; Scheme 2). The cytotoxic potential of NSpd and of its Pt(II)- and $\mathrm{Pd}(\mathrm{II})$-complexes has been evaluated [31], with quite promising results.

Regarding the vibrational characterization of NSpd, to the best of our knowledge only one attempt has been reported [23]. However, the vibrational assignments performed in that work are based on computational results obtained from calculations that, besides considering the incorrect form of NSpd form (the fully protonated one, which is definitely not the species occurring in pure condensed liquid phase), evidence significant inconsistencies. Hence, the herein reported work presents a comprehensive conformational study on NSpd, based on calculations that consider the non-protonated NSpd form and use the correct combination between molecular charge and multiplicity. The report culminates in a thorough reassessment of the vibrational assignment of the experimental FT-Raman and FTIR spectra.

\section{Experimental and computational details}

NSpd was purchased from Sigma-Aldrich Chemical Co (Sintra, Portugal) and used without further purification. 


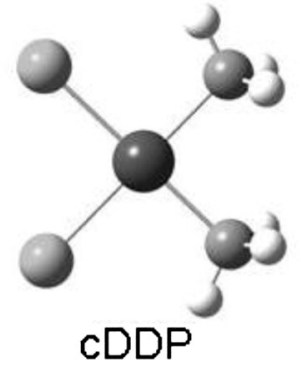

Scheme 1. Molecular structure of cisplatin.

\subsection{FTIR spectroscopy}

The Attenuated Total Reflection Infrared (ATR-FTIR) spectra were recorded on an IFS 55 spectrometer, using a Golden Gate single reflection diamond ATR system, with no need for sample preparation. All spectra are the average of two counts of 128 scans each. A spectral resolution of $2 \mathrm{~cm}^{-1}$ was used in all cases.

\subsection{FT-Raman spectroscopy}

The FT-Raman spectra were recorded on a RFS-100 Bruker FTspectrometer, using a Nd:YAG laser with excitation wavelength of $1064 \mathrm{~nm}$. The laser power was set to $150 \mathrm{~mW}$. Each spectrum is the averaging of two repeated measurements of 100 scans each at $2 \mathrm{~cm}^{-1}$ resolution.

\subsection{Quantum chemical calculations}

Optimization and vibrational gas-phase calculations were performed using the Gaussian 09w program (G09w) [32], installed in a PC machine. The hybrid DFT functional denoted by mPW1PW was used combined with the widely used 6-31G* electron basis set. The authors are aware of the smallness of the all electron basis set used. Its use is, nevertheless, justified for two main reasons. First, this work is enclosed within a wide project that aims to study polyamines, of progressively greater size and complexity, and the corresponding metal complexes. Given that comparisons are intended, it is desirable to maintain uniform the theoretical level considered. Moreover, an increase of the theoretical level complexity can quickly make quantum chemical calculations prohibitive, as the number of electrons of the system increases. On the other hand, the mPW1PW/6-31G* theory level has proven to yield reliable results for different amines and corresponding metal complexes, at the expense of an acceptable level of computational demands [18,20,22,26,28,29,33].

All geometries were submitted to full geometry optimization without any symmetry constraints, and subsequently to a vibrational frequency calculation to confirm its correspondence to a real minimum in the NSpd potential energy surface (no negative eigenvalue) and to quantify the zero-point vibrational energy correction (zpve).

In order to infer on the effects of the dielectric constant on the conformational preferences of NSpd, SCRF calculations (optimization and frequency) were performed within the PCM formalism (polarized continuum model). All default parameters were used except the radii model which was set as UAHF (for more details see [26]). This combination between Gaussian program version, SCRF formalism and atomic
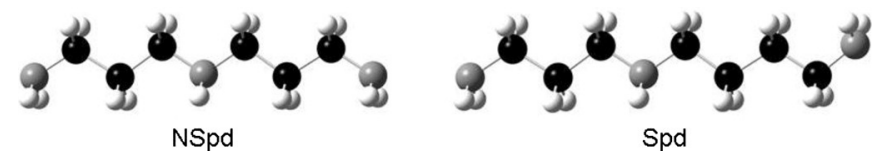

Scheme 2. Molecular structures of Norspermidine and Spermidine. radii model has proven to yield good results for isopropylamine (iPram) [26]. In the current study a wide variety of common solvents were selected in order to contemplate a broad range of dielectric constant values (at $25^{\circ} \mathrm{C}$ ). The full list of solvents considered and the corresponding dielectric constants [32,34] are given in Table S1 (Supplementary Material).

NBO analyses [35-37], as implemented in G09W [32], were also carried out for the optimized geometries, at selected dielectric constant values, in order to get a deeper insight into their electronic structures. Special attention was given to NBO Wiberg bond orders, dipole moments and second-order stabilization energies.

\section{Results and discussion}

\subsection{Conformational analysis}

Similarly to other linear alkylpolyamines, NSpd presents a high skeletal flexibility due to free rotation around the six skeletal dihedral angles, thus allowing a huge variety of possible molecular geometries. The most common values observed for the skeletal dihedral angles are $60^{\circ}$ (gauche, $\mathbf{G}$ ), $180^{\circ}$ (trans, $\mathbf{T}$ ) and $-60^{\circ}$ (gauche', $\mathbf{G}^{\prime}$ ). An identical variability $\left(60^{\circ}(\mathbf{g}), 180^{\circ}(\mathbf{t})\right.$ and $\left.-60^{\circ}\left(\mathbf{g}^{\prime}\right)\right)$ is found for the three LpN-CC torsional angles, Lp standing for nitrogen lone pair.

Theoretically, regarding only the skeletal torsional angles variability, there are 729 possibilities for the NSpd core structure. Due to centrosymmetry of NSpd and conformational degenerescence, the number of distinct possibilities is significantly reduced. From the 361 distinct molecular geometries assembled and submitted to optimization, a total of 270 were found to correspond to stable conformers (no negative eigenvalue) within the potential energy surface of NSpd. The remaining molecular structures either converged to one of the former or proved to be a saddle point (one negative eigenvalue). It should be noted that the variability of the LpN-CC torsional angles was not explicitly evaluated since it is hypothesised that, as no constraint is imposed, they will adopt the conformation leading to the greatest stability in the view of the overall skeleton configuration.

The gas-phase (isolated molecule) conformational study predicts the 270 conformers of NSpd to be distributed within a relative stability range of $c a .39 \mathrm{~kJ} \mathrm{~mol}^{-1}$, after zpve correction. Fig. 1 presents the variation of the relative stability $\left(\Delta \mathrm{E}_{\mathrm{rel}}\right)$ of the 13 most stable conformers which are found to lie within a range of $10 \mathrm{~kJ} \mathrm{~mol}^{-1}$. The relative position of the almost-fully trans conformation (tTTTg'TTTt), which occupies the $22 \mathrm{nd}$ position of the ranking $\left(\Delta \mathrm{E}_{\mathrm{rel}} \approx 12 \mathrm{~kJ} \mathrm{~mol}^{-1}\right)$ is included for the reason referred above. The molecular structures of the 14 conformers are presented in Fig. S1 (Supplementary Material) together with the conformational profile of both skeletal and LpN-CC torsional angles, and the $\mathrm{H} \cdots \mathrm{N}$ distances of the potentially stabilizing intramolecular $\mathrm{N}-\mathrm{H} \cdots \mathrm{N}$ hydrogen bonds. The LpN-CC torsional angle concerning the central amine group $(\mathrm{NH})$ is not indicated from now on, as the definition of the two skeletal torsional angles on both sides restrict the possibilities to $\mathrm{g}$ or $\mathrm{g}^{\prime}$.

The higher stability seems to be guaranteed by the occurrence of a t-g'-g' profile of the three LpN-CC torsional angles and a GG'T (or G' GT) skeletal configuration for at least one side of NSpd, taking the NH-group at the molecular middle (Fig. 1). The most stable conformer presents the GG'T skeletal conformation on both molecular sides ( $\mathrm{tGG}^{\prime} \mathrm{T}-\mathrm{TG}^{\prime} \mathrm{Gg}^{\prime}$ ). The higher stability is ensured by two intramolecular $\mathrm{N}-\mathrm{H} \cdots \mathrm{N}$ contacts, namely $\mathrm{N}_{\mathrm{t}}-\mathrm{H} \cdots \mathrm{N}(222.7 \mathrm{pm})$ and $\mathrm{N}_{\mathrm{c}}-\mathrm{H} \cdots \mathrm{N}^{\prime}$ (214.8 pm), where $\mathrm{N}_{\mathrm{t}}$ and $\mathrm{N}_{\mathrm{c}}$ stand for the terminal and central nitrogen atoms, respectively (Fig. S1). The coexistence of the two hydrogen bonds assures a higher stability for the $\mathrm{tGG}^{\prime} \mathrm{T}-\mathrm{TG}^{\prime} \mathrm{Gg}^{\prime}$ conformation of over $4.5 \mathrm{~kJ} \mathrm{~mol}^{-1}$, relatively to the second most stable conformer, $\mathrm{tTG}^{\prime} \mathrm{T}-\mathrm{TG}^{\prime} \mathrm{Gg}^{\prime}$ (Fig. 1).

One property known to affect the relative stability of conformers is the medium dielectric constant. NSpd solutions with a variety of solvents (Table S1 of the Supplementary Material) were simulated, by 


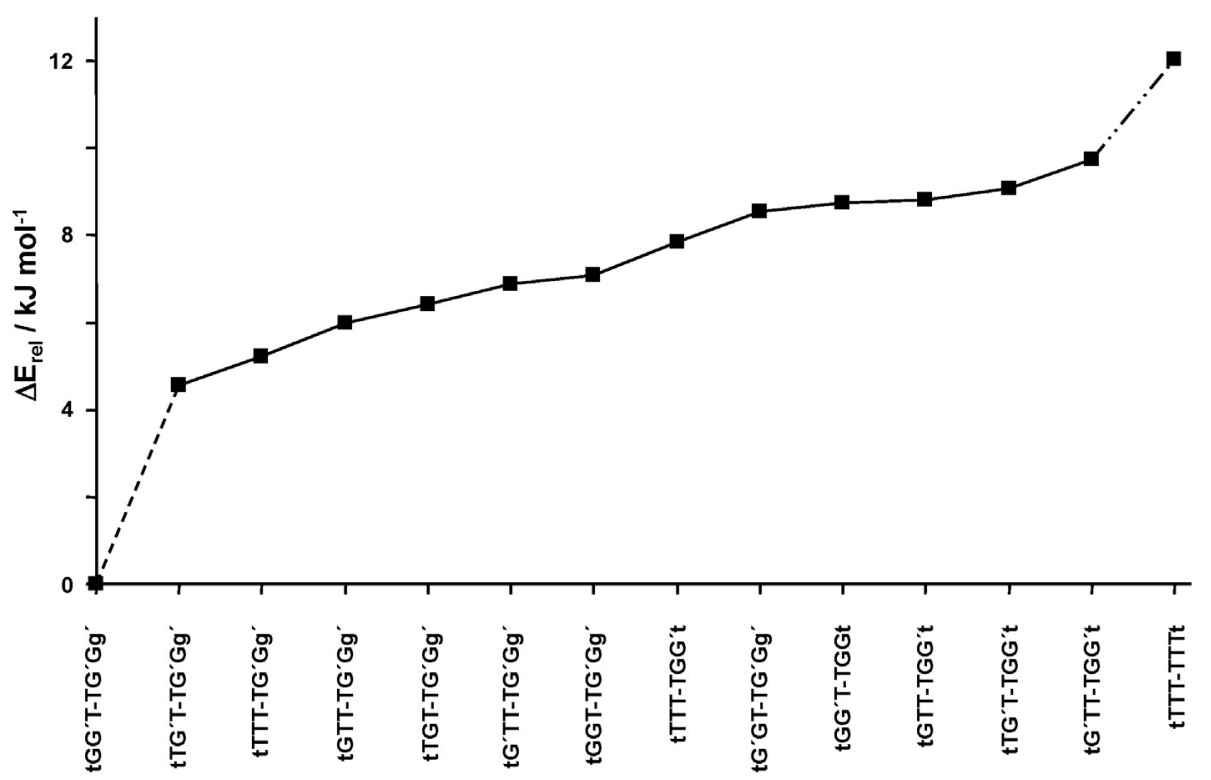

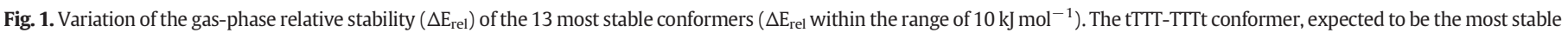
in the condensed phase, is also included for comparison.

considering medium dielectric constant $(\varepsilon)$ values ranging from 1 (vacuum; calculations for the isolated molecule) to 186 (N-methyl-formamide as solvent). The variation of the relative stabilities of two selected NSpd conformations (tTTT-TTTt and $\mathrm{tGG}^{\prime} \mathrm{T}-\mathrm{TG}^{\prime} \mathrm{Gg}$ ) was thus analysed as a function of the $\varepsilon$ values. The tTTT-TTTt conformation was considered alongside with the tGG' $\mathrm{T}-\mathrm{TG}{ }^{\prime} \mathrm{Gg}$, as it corresponds to the most stable conformation in the condensed liquid phase [17,19,38-41].

Fig. 2 presents the variation profile of the relative stability of the tTTT-TTTt conformer with respect to the tGG'T-TG' $\mathrm{Gg}^{\prime}$ one $\left(\Delta \mathrm{E}_{\mathrm{rel}}\right.$, in $\left.\mathrm{kJ} \mathrm{mol}^{-1}\right)$, as a function of the $\varepsilon$ value. By definition, positive $\Delta \mathrm{E}_{\mathrm{rel}}$ values indicate a higher stability of the $\mathrm{tGG}^{\prime} \mathrm{T}-\mathrm{TG}^{\prime} \mathrm{Gg}^{\prime}$ conformer whereas a negative value corresponds to a tTTT-TTTt greater stability. Curve fitting attempts showed that the best global adjustment is achieved with a second order exponential decay curve described as:

$\Delta E_{\text {rel }}=-11.190+8.097 \times \mathrm{e}^{-(\varepsilon / 14.553)}+25.967 \times \mathrm{e}^{-(\varepsilon / 1.910)}$

The associated $\mathrm{R}^{2}$ is 0.9995 , meaning that about $99.95 \%$ of the observed $\Delta \mathrm{E}_{\mathrm{rel}}$ decay (i.e., tTTT-TTTt stability increment relatively to $\mathrm{tGG}^{\prime}$

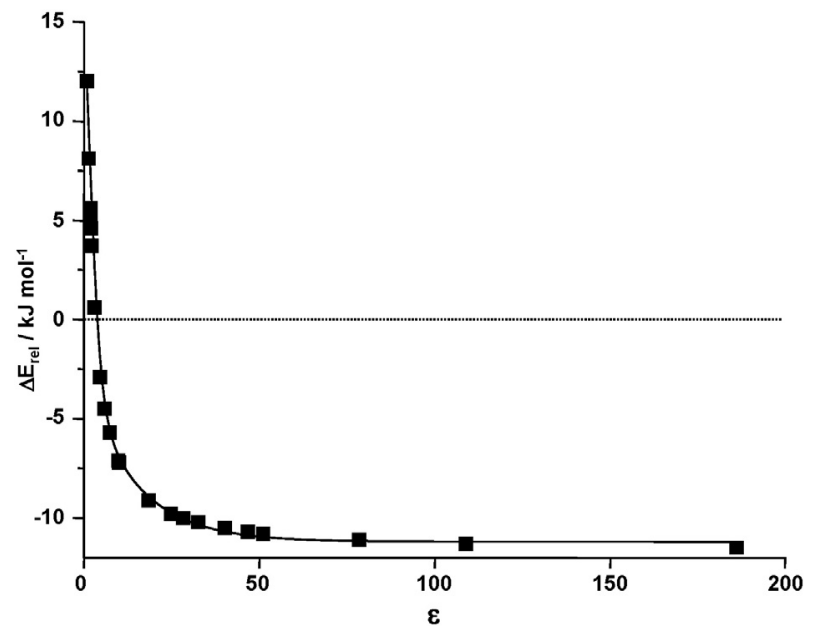

Fig. 2. Variation of relative stability $\left(\Delta \mathrm{E}_{\mathrm{rel}}\right)$ of the tTTT-TTTt conformer with respect to the conformer found to be the most stable in the gas-phase $\left(t G G^{\prime} T-\mathrm{TG}^{\prime} \mathrm{Gg}^{\prime}\right)$ as a function of dielectric constant $(\varepsilon)$
$\mathrm{T}-\mathrm{TG}^{\prime} \mathrm{Gg}^{\prime}$ ) is explained by variation in medium dielectric constant. According to the fitting equation, an inversion of the relative stability between the two conformers is expected to occur at a $\varepsilon$-value of $\approx 3.258$. This value will be referred to as the threshold value from now on.

In an attempt to understand the loss of stability of the $\mathrm{tGG}^{\prime} \mathrm{T}-\mathrm{TG}^{\prime}$ $\mathrm{Gg}^{\prime}$ conformer in relation to the tTTT-TTTt one, the length variations of the two stabilizing intramolecular interactions $\left(\mathrm{N}_{\mathrm{t}}-\mathrm{H} \cdots \mathrm{N}_{\mathrm{c}}\right.$ and $\mathrm{N}_{\mathrm{c}^{-}}$ $\mathrm{H} \cdots \mathrm{N}_{\mathrm{t}}{ }^{\prime}$ ) were assessed as a function of the dielectric constant. The distances in the isolated state (vacuum phase) were used as reference, being the length variations $\left(\Delta_{\mathrm{H} \cdots \mathrm{N}} ; \mathrm{pm}\right)$ determined as $\Delta_{\mathrm{H} \cdots \mathrm{N}}=\mathrm{d}_{\mathrm{H} \cdots \mathrm{N}}($ vacuum $)-\mathrm{d}_{\mathrm{H} \cdots \mathrm{N}}(\varepsilon)$. Therefore, a negative value of $\Delta_{\mathrm{H} \cdots \mathrm{N}}$ means an increase of the $\mathrm{H} \cdots \mathrm{N}$ distance on passing from the vacuum to a medium with a dielectric constant value $\varepsilon>1$.

Fig. 3 presents the plots of $\Delta_{H} \cdots N$ values of both $\mathrm{N}-\mathrm{H} \cdots \mathrm{N}$ interactions, as a function of $\varepsilon$ value. The effect of the dielectric constant is found to be significantly more pronounced for the $\mathrm{N}_{\mathrm{c}}-\mathrm{H} \cdots \mathrm{N}_{\mathrm{t}}{ }^{\prime}$ interaction than for the $\mathrm{N}_{\mathrm{t}}-\mathrm{H} \cdots \mathrm{N}_{\mathrm{c}}$ (Fig. 3). As for the $\Delta \mathrm{E}_{\text {rel }}$, in both cases the best fitting was achieved considering second-order exponential decay relationships. The fitting equations determined for the $\mathrm{N}_{\mathrm{t}}-\mathrm{H} \cdots \mathrm{N}$ and

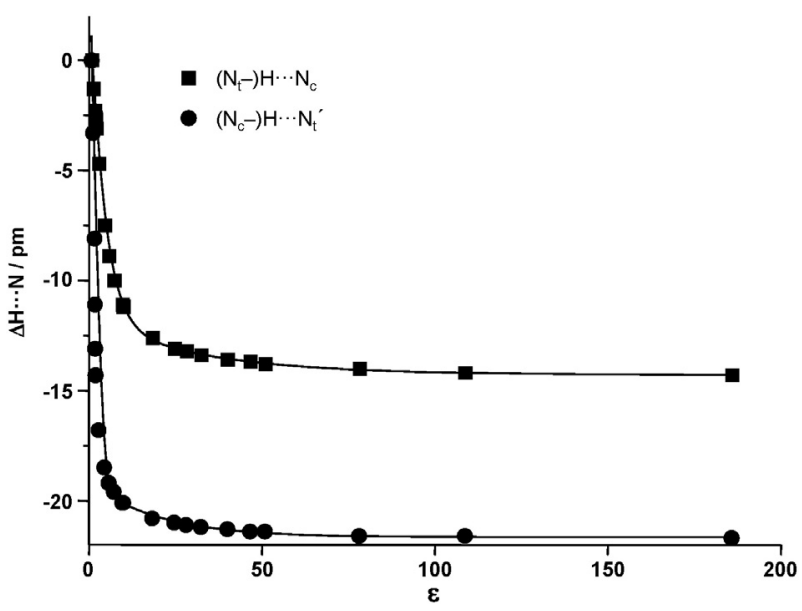

Fig. 3. Variation of the $H \cdots N$ distance $\left(\Delta H \cdots N\right.$, pm) of the $N_{t}-H \cdots N_{c}$ and $N_{c}-H \cdots N_{t}{ }^{\prime}$ hydrogen bonds in conformer $\mathrm{tGG}^{\prime} \mathrm{T}-\mathrm{TG}^{\prime} \mathrm{Gg}^{\prime}$ as a function of dielectric constant $(\varepsilon)$. The $\mathrm{H} \cdots \mathrm{N}$ distance predicted in the vacuum $(\varepsilon=1)$ is considered as reference. 
$\mathrm{N}_{\mathrm{c}}-\mathrm{H} \cdots \mathrm{N}^{\prime}$ interactions are

$\Delta_{\mathrm{H} \cdots \mathrm{N}}=-14.290+2.531 \times \mathrm{e}^{-(\varepsilon / 32.3616)}+15.332 \times \mathrm{e}^{-(\varepsilon / 3.978)} \mathrm{R}^{2}$ $=0.9998$

and

$\Delta_{\mathrm{H} \cdots \mathrm{N}}=-21.657+2.553 \times \mathrm{e}^{-(\varepsilon / 19.863)}+50.011 \times \mathrm{e}^{-(\varepsilon / 1.113)} \quad \mathrm{R}^{2}=0.9807$,

respectively. Considering the threshold $\varepsilon$-value, the $\Delta_{\mathrm{H} \cdots \mathrm{N}}$ values for the $\mathrm{N}_{\mathrm{t}}-\mathrm{H} \cdots \mathrm{N}_{\mathrm{c}}$ and $\mathrm{N}_{\mathrm{c}}-\mathrm{H} \cdots \mathrm{N}_{\mathrm{t}}{ }^{\prime}$ interactions are predicted to assume values of ca. -5.24 and $-16.81 \mathrm{pm}$, respectively. In other words, at a $\varepsilon$-value of 3.258 the $\mathrm{N}_{\mathrm{t}}-\mathrm{H} \cdots \mathrm{N}_{\mathrm{c}}$ and $\mathrm{N}_{\mathrm{c}}-\mathrm{H} \cdots \mathrm{N}_{\mathrm{t}}{ }^{\prime}$ hydrogen bond distances are expected to be lengthened from about 223 and $215 \mathrm{pm}$ (in the vacuum, Fig. S1) to ca. 228 and $232 \mathrm{pm}$, respectively. SCRF calculation performed for the $\mathrm{tGG}^{\prime} \mathrm{T}-\mathrm{TG}^{\prime} \mathrm{Gg}^{\prime}$ conformation at $\varepsilon=3.258$ retrieved $\left(\mathrm{N}_{\mathrm{t}}{ }^{-}\right) \mathrm{H} \cdots \mathrm{N}_{\mathrm{c}}$ and $\left(\mathrm{N}_{\mathrm{c}^{-}}\right) \mathrm{H} \cdots \mathrm{N}_{\mathrm{t}}{ }^{\prime}$ distances of 227.7 and $231.9 \mathrm{pm}$, respectively, clearly validating the fitting equations found.

Attempting to rationalize the effects underlying the lengthening predicted for the stabilizing hydrogen bonds with dielectric constant increase, NBO calculations were performed considering different values of $\varepsilon$. Special attention was given to the most significant second-order stabilization energies, dipole moments and Wiberg bond orders. Table 1 compiles the selected results as a function of conformer ( $t G G^{\prime} T-\mathrm{TG}^{\prime} \mathrm{Gg}^{\prime}$ and tTTT-TTTt) and dielectric constant (Table S1).

Starting with the second-order stabilization energies, the most relevant difference between the two conformers is the absence of the stabilizing delocalization between nitrogen electron lone pair and $\mathrm{N}-\mathrm{H}$ antibonding sigma orbital $\mathrm{LpN}_{\mathrm{c}} \rightarrow \sigma^{*} \mathrm{~N}_{\mathrm{t}}-\mathrm{H}$ and $\mathrm{LpN}_{\mathrm{t}} \rightarrow \sigma^{*} \mathrm{~N}_{\mathrm{c}}-\mathrm{H}$ in the tTTT-TTTt, regardless of the $\varepsilon$-value. In the vacuum, these orbital interactions contribute with a stabilization of 24 and $33 \mathrm{~kJ} \mathrm{~mol}^{-1}$, respectively, in the tGG'T-TG'Gg' conformation. Increasing dielectric constant promotes a gradual decrease of this stabilizing effect. At threshold $\varepsilon$-value the contribution of those orbital delocalizations are predicted to be reduced by over 12 and $39 \%$, respectively. The relevance of these orbital interactions for conformer stability has already been stressed out for other kind of aliphatic amines [25,42].

A similar behaviour is observed for the variation of the Wiberg bond indexes related to the $\left(\mathrm{N}_{\mathrm{t}^{-}}\right) \mathrm{H} \cdots \mathrm{N}_{\mathrm{c}}$ and $\left(\mathrm{N}_{\mathrm{c}^{-}}\right) \mathrm{H} \cdots \mathrm{N}_{\mathrm{t}}{ }^{\prime}$ interactions. Increase of dielectric constant from 1.00 (vacuum) to 3.258 reduces the $\mathrm{H} \cdots \mathrm{N}_{\mathrm{c}}$ and $\mathrm{H} \cdots \mathrm{N}_{\mathrm{t}}{ }^{\prime}$ Wiberg indexes by $\mathrm{ca}$. $3 \%$ and $c a .25 \%$, respectively. The sharper decrease predicted for both 2 nd-order stabilization energy and Wiberg index of the $\mathrm{N}_{\mathrm{c}}-\mathrm{H} \cdots \mathrm{N}_{\mathrm{t}}{ }^{\prime}$ interaction in comparison to the $\mathrm{N}_{\mathrm{t}}-$ $\mathrm{H} \cdots \mathrm{N}_{\mathrm{c}}$ interaction is in line with the relative effects observed for the $\Delta_{\mathrm{H} \cdots \mathrm{N}}$. (Fig. 3).

Regarding the dipole moments, increasing dielectric constant leads to an increase of the net dipole moment and delocalization contributions, regardless of the conformer. In both cases, the largest delocalization contribution to the dipole moment relates to the electron lone pairs of the nitrogen atoms. There is, however, a clear difference between the two conformers with respect to the variation profile of the delocalization contribution to the total dipole moment. In the case of the tTTT-TTTt conformer, the delocalization contribution gradually increases with dielectric constant, leading to an enhancement of the total dipole moment. In the case of the $\mathrm{tGG}^{\prime} \mathrm{T}-\mathrm{TG}^{\prime} \mathrm{Gg}^{\prime}$ the opposite is predicted.

The delocalization contributions tend to decrease as the medium dielectric constant increases. This leads to a smoothing of dipole moment increase with $\varepsilon$, as evidenced by the increasing proximity between net and total values of dipole moment. This distinct behaviour can at least

Table 1

Comparison of selected NBO results for the $t T T T g^{\prime} T T T t$ and $t G G^{\prime} T g^{\prime} T G^{\prime} G g^{\prime}$ conformers.

\begin{tabular}{|c|c|c|c|c|c|c|c|c|c|c|}
\hline \multirow{2}{*}{$\begin{array}{l}\text { NBO } \\
\text { Parameter }^{\mathrm{a}}\end{array}$} & \multicolumn{10}{|l|}{$\varepsilon$} \\
\hline & 1.00 & 2.228 & 3.0473 & $3.258^{\mathrm{b}}$ & 4.7113 & 10.125 & 32.613 & 46.826 & 78.3553 & 186.0 \\
\hline Second-order stabilization energies ${ }^{\mathrm{c}}$ & \multicolumn{10}{|c|}{ tTTTg'TTTt } \\
\hline $\mathrm{LpN}_{\mathrm{t}} \rightarrow \sigma^{*} \mathrm{C}_{1}-\mathrm{C}_{2}$ & 37 & 35 & 35 & 35 & 34 & 34 & 33 & 33 & 33 & 33 \\
\hline $\mathrm{LpN}_{\mathrm{t}} \rightarrow \sigma^{*} \mathrm{C}_{1}-\mathrm{H}^{\mathrm{d}}$ & $5 / 5$ & $4 / 4$ & $4 / 4$ & $4 / 4$ & $4 / 4$ & $4 / 4$ & $4 / 4$ & $4 / 4$ & $4 / 4$ & $4 / 4$ \\
\hline $\mathrm{LpN}_{\mathrm{c}} \rightarrow \sigma^{*} \mathrm{C}_{3}-\mathrm{H}$ & 36 & 35 & 34 & 34 & 34 & 33 & 33 & 33 & 33 & 33 \\
\hline $\mathrm{LpN}_{\mathrm{c}} \rightarrow \sigma^{*} \mathrm{C}_{3}-\mathrm{H}$ & 36 & 35 & 34 & 34 & 34 & 33 & 33 & 33 & 33 & 33 \\
\hline $\mathrm{LpN}_{\mathrm{c}} \rightarrow \sigma^{*} \mathrm{~N}_{\mathrm{t}}-\mathrm{H}$ & - & - & - & - & - & - & - & - & - & - \\
\hline $\mathrm{LpN}_{\mathrm{t}}^{\prime} \rightarrow \sigma^{*} \mathrm{C}_{1}^{\prime}-\mathrm{C}_{2}^{\prime}$ & 37 & 35 & 35 & 35 & 34 & 34 & 33 & 33 & 33 & 33 \\
\hline $\mathrm{LpN}_{\mathrm{t}}{ }^{\prime} \rightarrow \sigma^{*} \mathrm{C}_{1}{ }^{\prime}-\mathrm{H}^{\mathrm{d}}$ & $5 / 5$ & $4 / 4$ & $4 / 4$ & $4 / 4$ & $4 / 4$ & $4 / 4$ & $4 / 4$ & $4 / 4$ & $4 / 4$ & $4 / 4$ \\
\hline $\mathrm{LpN}_{\mathrm{t}}^{\prime} \rightarrow \sigma^{*} \mathrm{~N}_{\mathrm{c}}-\mathrm{H}$ & - & - & - & - & - & - & - & - & - & - \\
\hline \multicolumn{11}{|l|}{ Dipole moment } \\
\hline Net & 1.50 & 1.74 & 1.83 & 1.85 & 1.95 & 2.12 & 2.25 & 2.27 & 2.29 & 2.31 \\
\hline Delocalization correction & 0.78 & 0.79 & 0.80 & 0.80 & 0.81 & 0.82 & 0.84 & 0.84 & 0.84 & 0.85 \\
\hline Total & 1.87 & 2.17 & 2.28 & 2.31 & 2.43 & 2.63 & 2.79 & 2.82 & 2.84 & 2.86 \\
\hline Second-order stabilization energies ${ }^{c}$ & \multicolumn{10}{|c|}{$t G G^{\prime} T g^{\prime} T G^{\prime} G g^{\prime}$} \\
\hline $\mathrm{LpN}_{\mathrm{t}} \rightarrow \sigma^{*} \mathrm{C}_{1}-\mathrm{C}_{2}$ & 38 & 37 & 36 & 36 & 36 & 36 & 35 & 35 & 35 & 35 \\
\hline $\mathrm{LpN}_{\mathrm{c}} \rightarrow \sigma^{*} \mathrm{C}_{3}-\mathrm{H}$ & $34 / 5$ & $33 / 5$ & $32 / 5$ & $32 / 5$ & $32 / 5$ & $32 / 5$ & $31 / 5$ & $31 / 5$ & $31 / 5$ & $31 / 5$ \\
\hline $\mathrm{LpN}_{\mathrm{c}} \rightarrow \sigma^{*} \mathrm{C}_{3}{ }^{\prime}-\mathrm{H}$ & $36 / 7$ & $35 / 6$ & $34 / 6$ & $34 / 6$ & $34 / 6$ & $33 / 6$ & $33 / 5$ & $33 / 5$ & $33 / 5$ & $33 / 5$ \\
\hline $\mathrm{LpN}_{\mathrm{c}} \rightarrow \sigma^{*} \mathrm{~N}_{\mathrm{t}}-\mathrm{H}$ & 24 & 22 & 21 & 21 & 20 & 18 & 16 & 16 & 16 & 16 \\
\hline $\mathrm{LpN}_{\mathrm{t}}^{\prime} \rightarrow \sigma^{*} \mathrm{C}_{1}^{\prime}-\mathrm{H}$ & $31 / 3$ & $31 / 3$ & $31 / 3$ & $31 / 3$ & $31 / 3$ & $30 / 3$ & $30 / 3$ & $30 / 3$ & $30 / 3$ & $30 / 3$ \\
\hline $\mathrm{LpN}_{\mathrm{t}}{ }^{\prime} \rightarrow \sigma^{*} \mathrm{C}_{1}{ }^{\prime}-\mathrm{C}_{2}{ }^{\prime}$ & 5 & 4 & 4 & 4 & 4 & 4 & 4 & 4 & 4 & 3 \\
\hline $\mathrm{LpN}_{\mathrm{t}}^{\prime} \rightarrow \sigma^{*} \mathrm{~N}_{\mathrm{c}}-\mathrm{H}$ & 33 & 21 & 20 & 20 & 19 & 18 & 17 & 17 & 17 & 17 \\
\hline \multicolumn{11}{|l|}{ Dipole moment } \\
\hline Net & 3.89 & 4.12 & 4.20 & 4.21 & 4.29 & 4.40 & 4.47 & 4.47 & 4.48 & 4.49 \\
\hline Delocalization correction & 1.00 & 0.93 & 0.91 & 0.91 & 0.91 & 0.90 & 0.89 & 0.89 & 0.89 & 0.89 \\
\hline Total & 3.72 & 3.99 & 4.09 & 4.11 & 4.20 & 4.34 & 4.42 & 4.43 & 4.45 & 4.45 \\
\hline \multicolumn{11}{|l|}{ Wiberg index } \\
\hline$\left(\mathrm{N}_{\mathrm{t}}-\right) \mathrm{H} \cdots \mathrm{N}_{\mathrm{c}}$ & 0.0235 & 0.0234 & 0.0230 & 0.0229 & 0.0222 & 0.0210 & 0.0203 & 0.0203 & 0.0202 & 0.0201 \\
\hline$\left(\mathrm{N}_{\mathrm{c}^{-}}\right) \mathrm{H} \cdots \mathrm{N}_{\mathrm{t}}^{\prime}$ & 0.0275 & 0.0212 & 0.0205 & 0.0205 & 0.0203 & 0.0201 & 0.0200 & 0.0199 & 0.0199 & 0.0199 \\
\hline
\end{tabular}

Lp and $\sigma^{*}$ stand for lone pair and antibonding sigma orbital, respectively.

${ }^{a} \mathrm{~N}_{\mathrm{t}}$ and $\mathrm{N}_{\mathrm{t}}^{\prime}$ stand for terminal nitrogen atoms that act as donor and acceptor, respectively in the $t G G^{\prime} T g^{\prime} T G^{\prime} G g^{\prime}$ conformer (Fig. S1); for conformer $t T T T g^{\prime} T T T t$ they are equivalent.

b Critical $\varepsilon$-value.

c $\mathrm{In} \mathrm{kJ} \mathrm{mol}{ }^{-1}$.

d The two $\mathrm{H}$-atoms linked to $\mathrm{C}$-atom. 
partially explain the stability increase predicted for conformer tTTTTTTt, relative to conformer $\mathrm{tGG}^{\prime} \mathrm{T}-\mathrm{TG}^{\prime} \mathrm{Gg}^{\prime}$, as dielectric constant increases.

\subsubsection{Intermolecular hydrogen bonding effects}

In the condensed pure liquid phase, the likelihood of establishing intermolecular contacts is very high. In the case of amines, the $\mathrm{NH}_{2}$ and $\mathrm{NH}$ groups are particularly prone to the establishment of intermolecular $\mathrm{N}-\mathrm{H} \cdots \mathrm{N}$ hydrogen bonds. The relevance of these stabilizing interactions on the overall stability most likely overwhelms that of potential intramolecular interactions. In the case of NSpd, this would translate into a relative stability increase of the almost-fully trans conformation (tTTT-TTTt) which, in the limit, would become the more stable conformer. Therefore, it is important to evaluate the influence of the potential intermolecular $\mathrm{N}$ $\mathrm{H} \cdots \mathrm{N}$ contacts on the forecasts of the NSpd vibrational frequencies.

In order to evaluate the preferences of the $\mathrm{NH}_{2}$ and $\mathrm{NH}$ groups of NSpd for establishing intermolecular hydrogen bonding, six distinct molecular adduct models, based on the tTTT-TTTt conformation, were assembled and fully optimized. In all those models, the NSpd partners in the hydrogen bonding are ammonia molecules, in order to maintain the computational demands low. In the two smallest adduct models, each terminal $\mathrm{NH}_{2}$-group is involved in two $\mathrm{N}-\mathrm{H} \cdots \mathrm{N}$ interactions, with two distinct $\mathrm{NH}_{3}$ molecules, acting simultaneously as donors and acceptors (d-a H-bond profile), while the central $\mathrm{NH}$ group is involved in one $\mathrm{N}-\mathrm{H} \cdots \mathrm{N}$ interaction, acting either as a donor (model 1) or as an acceptor (model 2). All the attempts made to optimize adducts with the terminal $\mathrm{NH}_{2}$-group acting as double donors (d-d H-bond profile) failed, always converging to a d-a $\mathrm{H}$-bond profile. This inability to optimize the d-d H-bond profile evidences the preference of the $\mathrm{NH}_{2}$ groups for a d-a arrangement, in line with the results previously reported for iPram [28].

Model 3 differs from the preceding insofar as the central NH group also presents a d-a H-bonding profile. In the next two models, the hydrogen bonding capacities of the $\mathrm{NH}_{2}$ groups are fully satisfied (d-a-d $\mathrm{H}$-bond profile), wherein the NH group acts either as acceptor (model 4 ) or donor (model 5). Finally, in the larger adduct model (model 6), the maximum $\mathrm{H}$-bonding capacities of both $\mathrm{NH}_{2}$ and $\mathrm{NH}$ groups are completely contemplated. Fig. 4 presents the optimized geometries determined all six $\mathrm{NSpd} \cdot \mathrm{NH}_{3}$ adduct models, along with the distances characterizing the $\mathrm{N}-\mathrm{H} \cdots \mathrm{N}$ intermolecular interactions established.

In view of getting insights on the stabilizing effects of the distinct hydrogen bonding patterns considered, two energetic parameters were
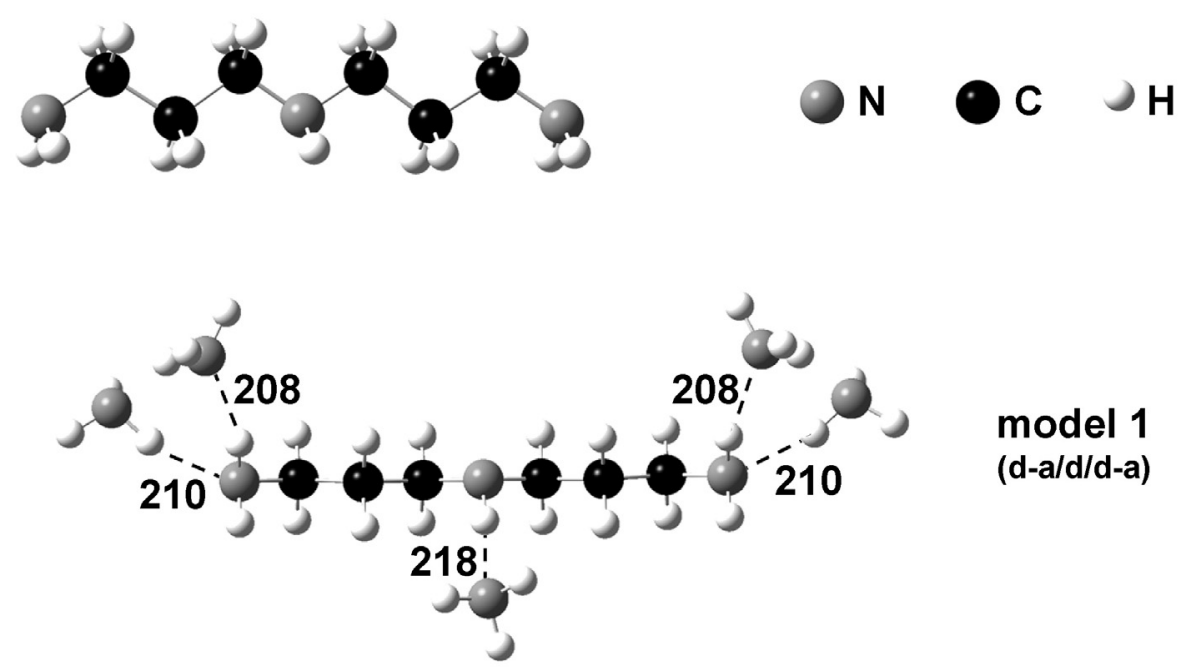

model 1

(d-a/d/d-a)

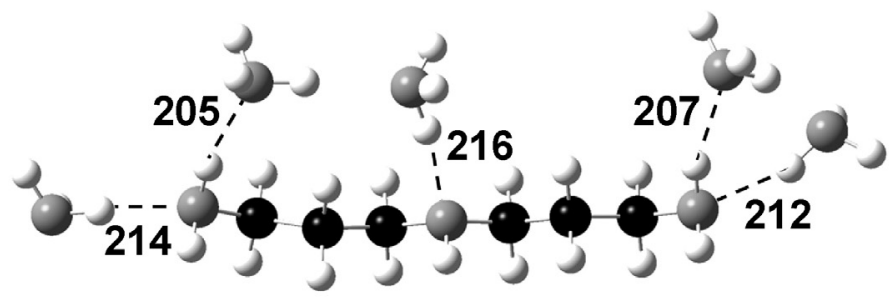

model 2

(d-a/a/d-a)

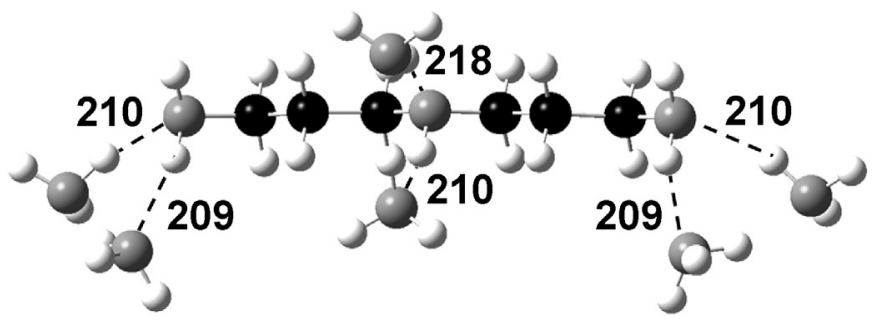

model 3

(d-a/d-a/d-a)

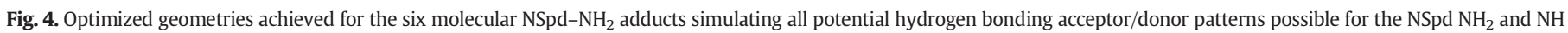
groups. The $\mathrm{H}$-bond distances between $\mathrm{NSpd}$ and surrounding $\mathrm{NH}_{3}$ molecules are indicated (in pm). 


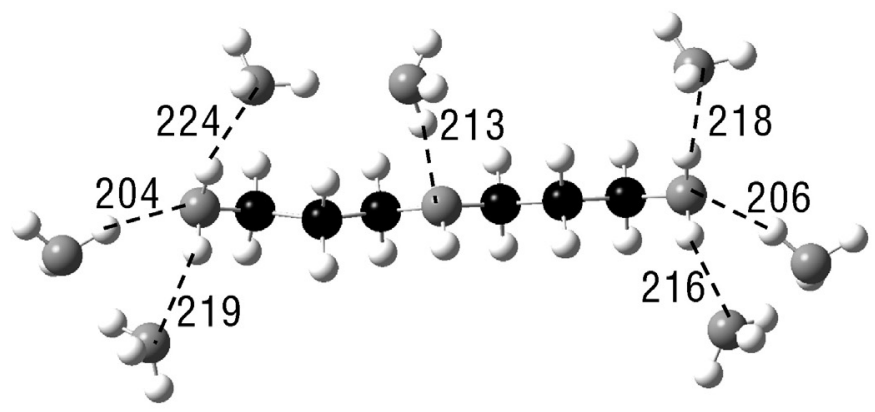

model 4
$(d-a-d / a / d-a-d)$

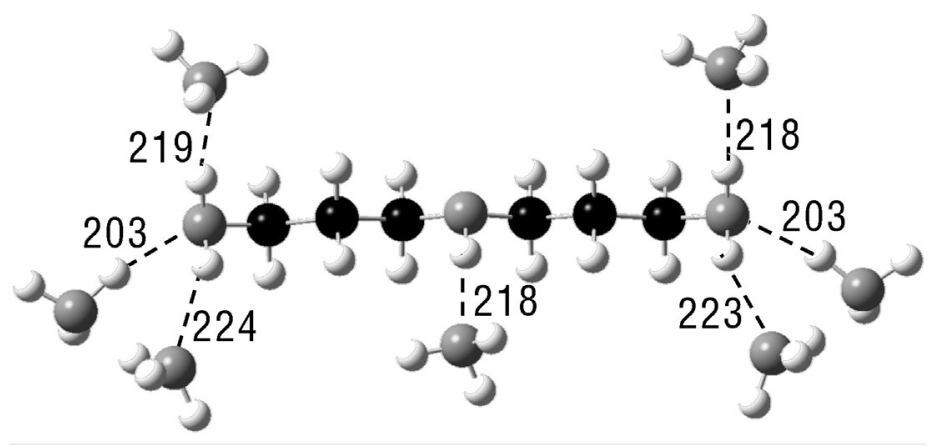

$\operatorname{model} 5$
$(d-a-d / d / d-a-d)$

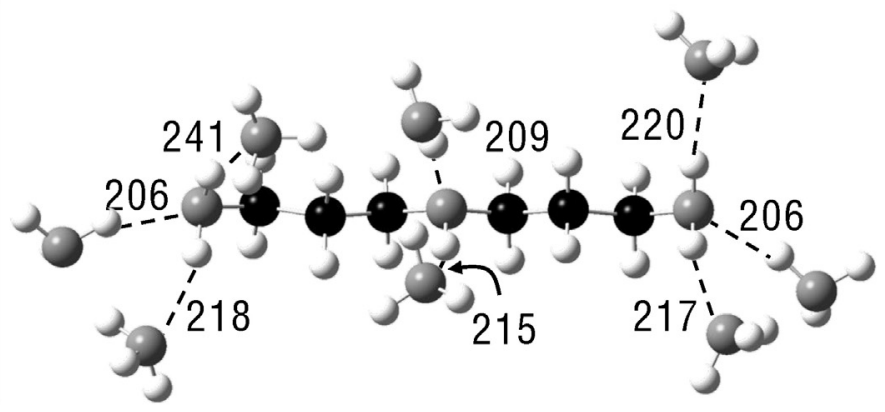

\author{
model 6 \\ $(d-a-d / d-a / d-a-d)$
}

Fig. 4 (continued).

evaluated, namely the adduct formation energy $\left(\Delta \mathrm{E}_{\text {adduct }}\right)$ and the cooperativity effect between multiple H-bonds (CEHB). These energetic parameters were quantified as previously for iPram [28], using expressions (1) and (2), respectively

$\Delta \mathrm{E}_{\text {adduct }}=-\left[\mathrm{E}_{\text {adduct }}-\left(\mathrm{E}_{\mathrm{NSpd}}+\mathrm{n} \times \mathrm{E}_{\mathrm{NH}_{3}}\right)\right]$

$\mathrm{CEHB}_{\text {adduct }}=\Delta \mathrm{E}_{\text {adduct }}-\left(\left(\mathrm{i} \times \Delta \mathrm{E}_{\left(\mathrm{NH}_{2}\right)_{\mathrm{d}}}+\mathrm{j} \times \Delta \mathrm{E}_{\left(\mathrm{NH}_{2}\right)_{a}}+\mathrm{k} \times \Delta \mathrm{E}_{\left(\mathrm{NH}_{d}\right.}+\mathrm{l} \times \Delta \mathrm{E}_{\left(\mathrm{NH}_{\mathrm{a}}\right.}\right)\right.$,

where $\mathbf{n}$ stands for the number of $\mathrm{NH}_{3}$ molecules of the adduct, $\mathbf{i}$ and $\mathbf{j}$ stand for the number of times the terminal $\mathrm{NH}_{2}$ groups act as donor and acceptor, respectively, and $\mathbf{k}$ and $\mathbf{l}$ stand for the number of times the central NH group acts as donor or acceptor, respectively. The values of $\Delta E_{\left(\mathrm{NH}_{2}\right) d}, \Delta E_{\left(\mathrm{NH}_{2}\right) a}, \Delta E_{(\mathrm{NH}) d}$ and $\Delta E_{(\mathrm{NH}) a}$ were determined following Eq. (1), considering the energies obtained in the calculations performed for adducts presenting a NSpd-to- $\mathrm{NH}_{3}$ stoichiometry of $1: 1$ with the $\mathrm{H}$ bond style indicated in subscript (involving either the $\mathrm{NH}_{2}$ or the $\mathrm{NH}$ group, as acceptor, a, or as donor, $\mathbf{d}$ ).

According to the calculations performed for the 1:1 NSpd-to- $\mathrm{NH}_{3}$ adducts, a donor involvement of the $\mathrm{NH}_{2}$ groups provides a greater adduct stability by ca. $1.2 \mathrm{~kJ} \mathrm{~mol}^{-1}$, with respect to the acceptor involvement. Regarding the NH group, no preference is highlighted, the predicted energy difference between the two types of adducts
$\left(\Delta E_{(N H) d} v s . \Delta E_{(N H) a}\right)$ being less than $0.05 \mathrm{~kJ} \mathrm{~mol}^{-1}$. This independence of the $\mathrm{NH}$ group with regard to the type of participation in hydrogen bonding does not stand when the more complex adduct models are considered (Fig. 4).

Fig. 5 shows the variation of both $\Delta \mathrm{E}_{\text {adduct }}$ and CEHB parameters as a function of adduct model (Fig. 4). Opposing to what was observed for the $1: 1$ adducts, the preference of the $\mathrm{NH}$ group for an acceptor $\mathrm{H}$ -

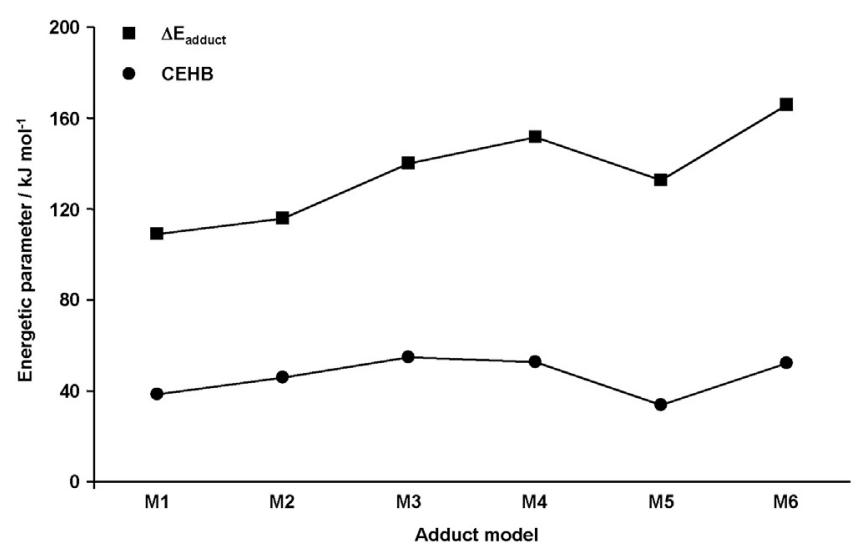

Fig. 5. Variation of the $\Delta \mathrm{E}_{\text {adduct }}$ and CEHB values as a function of adduct model (for definition of the $\Delta \mathrm{E}_{\text {adduct }}$ and CEHB values see text). 
bond involvement is evident. This stands regardless of whether the maximum engagement capacities of the terminal $\mathrm{NH}_{2}$ groups are fulfilled or not. Comparing the $\Delta \mathrm{E}_{\text {adduct }}$ values determined for the two smaller adduct models, the acceptor involvement of the $\mathrm{NH}$ group (model 2) is predicted to be stabilized by more than $7 \mathrm{~kJ} \mathrm{~mol}^{-1}$ with respect to a donor-type participation (model 1). This stabilization effect of the $\mathrm{NH}$ acceptor-like involvement is significantly accentuated when the hydrogen bonding capacities of the terminal $\mathrm{NH}_{2}$ are fulfilled (model 4 vs. model 5).

Usually, increasing the number of molecules within the adducts is expected to increase $\Delta \mathrm{E}_{\text {adduct }}[28,43,44]$. This general rule is observed in the present work with only one exception, when passing from adduct model 3 to adduct model 5, in which case, the calculations predict a $\Delta \mathrm{E}_{\text {adduct }}$ reduction of about $13 \mathrm{~kJ} \mathrm{~mol}^{-1}$. This result evidences a destabilizing effect of the $\mathrm{NH}$ involvement as a donor, thus emphasizing the preference of the of an acceptor-like involvement.

Fulfilling the hydrogen bonding capacity of both primary and secondary amine groups (model 6) increases the adduct formation energy (116 kJ mol ${ }^{-1}$ in model 2 vs. $166 \mathrm{~kJ} \mathrm{~mol}^{-1}$ in model 6). However, this effect is clearly not due to an enhancement of the positive cooperative effect between the multiple H-bonds. As seen in Fig. 5, a maximum CEHB is achieved in adduct model 3. Passing from adduct model 3 $\left(\mathrm{CEHB}=55 \mathrm{~kJ} \mathrm{~mol}^{-1}\right.$ ) to adduct models 4 to 6 leads to CEHB drops of 3,21 and $3 \mathrm{~kJ} \mathrm{~mol}^{-1}$, respectively. This means that maximum positive H-bond cooperativity in NSpd is expected if two premises are met: (i) the H-bonding capacity of the $\mathrm{NH}$ group is fulfilled (d-a pattern) and (ii) the $\mathrm{NH}_{2} \mathrm{H}$-bond involvement is also a d-a pattern (i.e., $\mathrm{H}$ bond involvement capacity not fully satisfied). Te later is in accordance with the results previously reported for the hydrogen bonding preferences of the $\mathrm{NH}_{2}$ group in iPram [28].

\subsection{Vibrational analysis}

NSpd presents a total of 72 vibrational modes. The 13 lowest frequency vibrations correspond to the skeletal deformations, namely 7 longitudinal and 6 transversal acoustic modes (LAMs and TAMs, respectively). The assignment of these low frequency vibrations exclusively based on the Raman spectra can be rather arguable, their identification being more surest using the complementary INS technique $[17,19]$. Moreover, these low-frequency vibrational modes are highly overlapped by the lattice vibrations in the molecular adducts. Therefore, they are not addressed in the present study.

The remaining 59 vibrational modes correspond to 25 stretchings ( 4 $\nu \mathrm{NH}_{2}, 12 \nu \mathrm{CH}_{2}, 1 \nu \mathrm{NH}, 2 \nu \mathrm{C}-\mathrm{NH}_{2}, 2 \nu \mathrm{C}-\mathrm{NH}$ and $4 \nu \mathrm{C}-\mathrm{C}$ ), 8 scissorings ( 2 $\delta \mathrm{NH}_{2}$ and $6 \delta \mathrm{CH}_{2}$ ), 8 waggings $\left(2 \omega \mathrm{NH}_{2}\right.$ and $6 \omega \mathrm{CH}_{2}$ ), 8 twistings (2 $\mathrm{tNH}_{2}$ and $\left.6 \mathrm{tCH}_{2}\right)$ and 8 rockings $\left(2 \mathrm{NHH}_{2}\right.$ and $\left.6 \rho \mathrm{CH}_{2}\right)$, and 1 in-plane and 1 out-of-plane $\mathrm{N}-\mathrm{H}$ deformations ( $\beta \mathrm{NH}$ and $\gamma \mathrm{NH}$, respectively).

The effects of the involvement of amine groups in hydrogen bonding on the predictions of the corresponding vibrational frequencies have been extensively assessed, both experimentally and theoretically [18, $28,33,45-48]$. A recent quantum chemical study performed on iPram [28], for instance, showed that the $\mathrm{NH}_{2}$ involvement in intermolecular $\mathrm{N}-\mathrm{H} \cdots \mathrm{N}$ interactions has a pronounced effect on the $\mathrm{NH}_{2}$ stretching, wagging and rocking modes. The remaining vibrational modes were found to be comparatively much less affected, with those ascribed to the $\mathrm{CH}_{2}$-groups remaining almost unaffected. Concordant results were recently reported regarding the effects of the interactions with counterions on the vibrational frequencies of $\alpha, \omega$-diamines hydrochloride salts [33].

Table 2 presents and compares the non-scaled vibrational frequencies calculated for NSpd in the isolated form and within the six molecular adducts tested. The deviations promoted by the distinct hydrogen bonding patterns on each NSpd vibrational mode, relative to the isolated state $\left(\Delta=\omega_{\text {adduct }}-\omega_{\text {NSpd }}\right)$, are also presented. Assignments were made on the basis of the atomic displacements predicted and visualized using the GaussView program package [49].
In line with other reported works [18,28,33,50,51], the effects of the intermolecular $\mathrm{N}-\mathrm{H} \cdots \mathrm{N}$ interactions are particularly noticed on the $v_{s} \mathrm{NH}_{2}, v_{\text {as }} \mathrm{NH}_{2}, \omega \mathrm{NH}_{2}, \rho \mathrm{NH}_{2}, \nu \mathrm{NH}$ and $\gamma \mathrm{NH}$. While the stretching modes $\left(v_{s} \mathrm{NH}_{2}, v_{\text {as }} \mathrm{NH}_{2}\right.$ and $\left.\nu \mathrm{NH}\right)$ are pronouncedly red-shifted, all remaining modes are blue-shifted. The magnitude of the deviations is clearly dependent on the degree (number of established interactions) and type (acceptor $v$ s. donor) of participation of the $\mathrm{NH}$ and $\mathrm{NH}_{2}$ groups within the overall hydrogen bonding network.

Regarding the H-bonding of the central NH group, its involvement as an acceptor was found to have a relatively small effect on any of the three related vibrational modes, $\nu \mathrm{NH}, \beta \mathrm{NH}$ and $\gamma \mathrm{NH}$ (isolated NSpd vs. adduct models 2 and 4). In contrast, its donor-like involvement leads to significant downward and upward shifts of the $\nu \mathrm{NH}$ and $\gamma \mathrm{NH}$ modes, respectively. The effect of cooperativity between the hydrogen bonds involving the $\mathrm{NH}$ group and the hydrogen bonds involving the $\mathrm{NH}_{2}$ groups seems to be negligible. In fact, the deviations predicted for the $\nu \mathrm{NH}$ and $\gamma \mathrm{NH}$ modes for the $1: 1$ $\mathrm{NSpd} \cdot \mathrm{NH}_{3}$ molecular adduct (presenting the $\mathrm{NH}$ group involved in a $\mathrm{H}$-bond with $\mathrm{NH}_{3}$ as a donor; not shown) are of the same magnitude as those predicted for adduct models 1 and 5 ( $\nu \mathrm{NH}$ : $-92 \mathrm{~cm}^{-1}$ vs. $-90 \mathrm{~cm}^{-1}$ (model 1) and $-94 \mathrm{~cm}^{-1}$ (model 5); үNH: $132 \mathrm{~cm}^{-1}$ vs. $127 \mathrm{~cm}^{-1}$ (model 1) and $139 \mathrm{~cm}^{-1}$ (model 5)). However, the same is not observed when the effect of cooperativity between two hydrogen bonds centred at the $\mathrm{NH}$ group (d-a profile) is evaluated. In this case, H-bonding cooperativity enhances the frequency deviations, as evidenced by the change of model 1 to model 3 or of model 5 to model 6 . Interestingly, the maximum effect of $\mathrm{H}$ bonding cooperativity on the magnitude of the deviations is observed when model 1 is transformed into model 3, which corresponds to the adduct model displaying the highest CEHB value.

Considering the $\mathrm{NH}_{2}$ most affected vibrational modes $\left(\nu_{\mathrm{s}} \mathrm{NH}_{2}\right.$, $v_{\mathrm{as}} \mathrm{NH}_{2}, \omega \mathrm{NH}_{2}$ and $\rho \mathrm{NH}_{2}$ ), the calculations performed for the $1: 1$ $\mathrm{NSpd} \cdot \mathrm{NH}_{3}$ molecular adduct presenting the $\mathrm{NH}_{2}$ group engaged in the $\mathrm{H}$-bond to the $\mathrm{NH}_{3}$ molecule (results not shown) suggest that, as for the $\mathrm{NH}$ vibrations, acceptor involvement has in general a very smooth effect. The only exception is observed for the $\mathrm{\rho NH}_{2}$ mode, for which an acceptor-like involvement of the $\mathrm{NH}_{2}$ group leads to a blue-shift of $192 \mathrm{~cm}^{-1}$. On the other hand, the donor involvement of the $\mathrm{NH}_{2}$ group in a 1:1 NSpd $\cdot \mathrm{NH}_{3}$ molecular adduct leads to slightly larger deviations, though only the $\mathrm{\rho NH}_{2}$ mode is shifted by more than $100 \mathrm{~cm}^{-1}$ (results not shown).

Enhancing the $\mathrm{NH}_{2}$ participation in the H-bonding pattern, while keeping the $\mathrm{NH}$ involvement $(1: 1 \rightarrow$ model $1 \rightarrow$ model 5 or $1: 1 \rightarrow$ model $2 \rightarrow$ model 4 ), progressively accentuates the deviation of the $v_{\mathrm{as}} \mathrm{NH}_{2}, \omega \mathrm{NH}_{2}$ and $\rho \mathrm{NH}_{2}$. The $\nu_{\mathrm{s}} \mathrm{NH}_{2}$, in turn, shows pronounced deviation that increases when going from adduct 1:1 to either models 1 or 2 , but evidence the opposite when comparing models 1 and 2 with models 4 and 5 , respectively. Fulfilling the hydrogen bonding capacity of the $\mathrm{NH}$ group (model $5 \rightarrow$ model 6 ) does not change the variation trends described.

In short, the results currently presented reinforce the idea, vastly reported in the literature, intermolecular interactions, as hydrogen bonding, may significantly affect the spectral position of certain vibrational modes. Therefore, it is extremely important that those effects are taken into account when allocating experimentally observed spectral features based on the theoretical spectral forecasts. Therefore, the next section presents a reassessment of the vibrational assignments already reported in the literature, given that the energy assessment made in this work pointed adduct model 3 as ensuring a higher overall stability, judging by the greater $\mathrm{H}$-bonding cooperativity predicted (larger CEHB value).

\subsubsection{Assignment of the experimental vibrational spectra}

Fig. 6 shows the vibrational spectra (FT-Raman and FTIR) of pure liquid NSpd, in the $100-1750 \mathrm{~cm}^{-1}$ and $2250-3750 \mathrm{~cm}^{-1}$ spectral regions. Table 3 presents the vibrational assignments for NSpd, based on the 
Table 2

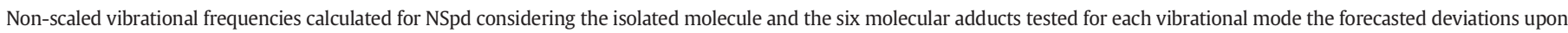

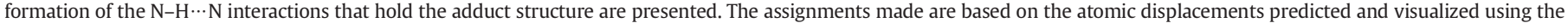
GaussView program [49].

\begin{tabular}{|c|c|c|c|c|c|c|c|c|c|c|c|c|c|}
\hline \multirow[t]{3}{*}{ NSpd } & \multicolumn{12}{|c|}{ Molecular adducts $^{\mathrm{a}}$} & \multirow[t]{3}{*}{ Vibrational assignment } \\
\hline & \multicolumn{2}{|c|}{ Model 1} & \multicolumn{2}{|c|}{ Model 2} & \multicolumn{2}{|c|}{ Model 3} & \multicolumn{2}{|c|}{ Model 4} & \multicolumn{2}{|c|}{ Model 5} & \multicolumn{2}{|c|}{ Model 6} & \\
\hline & $\omega^{\mathrm{b}}$ & $\Delta^{\mathrm{c}}$ & $\omega^{\mathrm{b}}$ & $\Delta^{\mathrm{c}}$ & $\omega^{\mathrm{b}}$ & $\Delta^{\mathrm{c}}$ & $\omega^{\mathrm{b}}$ & $\Delta^{\mathrm{c}}$ & $\omega^{\mathrm{b}}$ & $\Delta^{\mathrm{c}}$ & $\omega^{\mathrm{b}}$ & $\Delta^{\mathrm{c}}$ & \\
\hline 3599 & 3554 & -45 & 3555 & -44 & 3554 & -45 & 3480 & -119 & 3488 & -111 & 3490 & -109 & $v_{\text {as }} \mathrm{NH}_{2}$ \\
\hline 3599 & 3552 & -47 & 3555 & -44 & 3554 & -45 & 3472 & -127 & 3486 & -113 & 3487 & -112 & \\
\hline 3509 & 3387 & -122 & 3372 & -137 & 3376 & -133 & 3394 & -115 & 3406 & -103 & 3400 & -109 & $v_{\mathrm{s}} \mathrm{NH}_{2}$ \\
\hline 3509 & 3378 & -131 & 3315 & -194 & 3376 & -133 & 3390 & -119 & 3404 & -105 & 3399 & -110 & \\
\hline 1713 & 1747 & 34 & 1748 & 35 & 1746 & 33 & 1762 & 49 & 1761 & 48 & 1762 & 49 & $\delta \mathrm{NH}_{2}$ \\
\hline 1713 & 1746 & 33 & 1732 & 19 & 1746 & 33 & 1754 & 41 & 1761 & 48 & 1758 & 45 & \\
\hline 898 & 1000 & 102 & 1005 & 107 & 1023 & 125 & 1030 & 132 & 1024 & 126 & 1028 & 130 & $\omega \mathrm{NH}_{2}$ \\
\hline 896 & 992 & 96 & 993 & 97 & 998 & 102 & 1007 & 111 & 1014 & 118 & 1020 & 124 & \\
\hline 1055 & 1078 & 23 & 1074 & 19 & 1066 & 11 & 1090 & 35 & 1093 & 38 & 1091 & 36 & $\mathrm{t} \mathrm{NH}_{2}$ \\
\hline 1035 & 1056 & 21 & 1045 & 10 & 1054 & 19 & 1056 & 21 & 1076 & 41 & 1075 & 40 & \\
\hline 306 & 629 & 323 & 650 & 344 & 628 & 322 & 693 & 387 & 681 & 375 & 684 & 378 & $\rho \mathrm{NH}_{2}$ \\
\hline 306 & 626 & 320 & 630 & 324 & 626 & 320 & 687 & 381 & 678 & 372 & 661 & 355 & \\
\hline 3520 & 3430 & -90 & 3519 & -1 & 3349 & -171 & 3515 & -5 & 3426 & -94 & 3402 & -118 & $v \mathrm{NH}$ \\
\hline 1524 & 1592 & 68 & 1514 & -10 & 1601 & 77 & 1514 & -10 & 1592 & 68 & 1583 & 59 & $\beta \mathrm{NH}$ \\
\hline 809 & 936 & 127 & 833 & 24 & 980 & 171 & 846 & 37 & 948 & 139 & 971 & 162 & $\gamma \mathrm{NH}$ \\
\hline 3120 & 3119 & -1 & 3138 & 18 & 3118 & -2 & 3145 & 15 & 3116 & -4 & 3137 & 17 & $v_{\text {as }} \mathrm{CH}_{2}$ \\
\hline 3120 & 3117 & -3 & 3116 & -4 & 3117 & -3 & 3114 & -6 & 3114 & -6 & 3114 & -6 & \\
\hline 3095 & 3093 & -2 & 3096 & 1 & 3092 & -3 & 3090 & -5 & 3083 & -12 & 3092 & -3 & \\
\hline 3095 & 3091 & -4 & 3091 & -4 & 3092 & -3 & 3084 & -11 & 3081 & -14 & 3081 & -14 & \\
\hline 3077 & 3064 & -13 & 3076 & -1 & 3056 & -21 & 3075 & -2 & 3063 & -14 & 3055 & -22 & \\
\hline 3074 & 3059 & -15 & 3074 & 0 & 3055 & -19 & 3073 & -1 & 3061 & -13 & 3052 & -22 & \\
\hline 3067 & 3055 & -12 & 3060 & -7 & 3062 & -5 & 3055 & -12 & 3049 & -18 & 3070 & 3 & $v_{\mathrm{s}} \mathrm{CH}_{2}$ \\
\hline 3067 & 3053 & -14 & 3054 & -13 & 3061 & -6 & 3053 & -14 & 3048 & -19 & 3063 & -4 & \\
\hline 3040 & 3051 & 11 & 3051 & 11 & 3053 & 13 & 3047 & 7 & 3046 & 6 & 3050 & 10 & \\
\hline 3040 & 3044 & 4 & 3045 & 5 & 3052 & 12 & 3047 & 7 & 3045 & 5 & 3045 & 5 & \\
\hline 2952 & 2927 & -25 & 2975 & 23 & 2953 & 1 & 2975 & 23 & 2925 & -27 & 2966 & 14 & \\
\hline 2947 & 2920 & -27 & 2968 & 21 & 2946 & 1 & 2968 & 21 & 2919 & -28 & 2955 & 8 & \\
\hline 1559 & 1559 & 0 & 1558 & -1 & 1557 & -2 & 1558 & -1 & 1559 & 0 & 1558 & -1 & $\delta \mathrm{CH}_{2}$ \\
\hline 1547 & 1546 & -1 & 1547 & 0 & 1545 & -2 & 1547 & 0 & 1546 & -1 & 1547 & 0 & \\
\hline 1532 & 1533 & 1 & 1532 & 0 & 1532 & 0 & 1532 & 0 & 1532 & 0 & 1534 & 2 & \\
\hline 1530 & 1530 & 0 & 1530 & 0 & 1529 & -1 & 1530 & 0 & 1530 & 0 & 1530 & 0 & \\
\hline 1518 & 1520 & 2 & 1521 & 3 & 1519 & 1 & 1521 & 3 & 1519 & 1 & 1522 & 4 & \\
\hline 1517 & 1519 & 2 & 1519 & 2 & 1518 & 1 & 1519 & 2 & 1518 & 1 & 1519 & 2 & \\
\hline 1458 & 1457 & -1 & 1455 & -3 & 1456 & -2 & 1452 & -6 & 1454 & -4 & 1453 & -5 & $\omega \mathrm{CH}_{2}$ \\
\hline 1431 & 1428 & -3 & 1430 & -1 & 1427 & -4 & 1430 & -1 & 1427 & -4 & 1430 & -1 & \\
\hline 1418 & 1415 & -3 & 1417 & -1 & 1414 & -4 & 1417 & -1 & 1414 & -4 & 1414 & -4 & \\
\hline 1396 & 1397 & 1 & 1394 & -2 & 1398 & 2 & 1392 & -4 & 1396 & 0 & 1393 & -3 & \\
\hline 1311 & 1311 & 0 & 1326 & 15 & 1314 & 3 & 1319 & 8 & 1310 & -1 & 1321 & 10 & \\
\hline 1284 & 1287 & 3 & 1288 & 4 & 1291 & 7 & 1292 & 8 & 1287 & 3 & 1292 & 8 & \\
\hline 1418 & 1437 & 19 & 1449 & 31 & 1437 & 19 & 1463 & 45 & 1453 & 5 & 1454 & 36 & $\mathrm{t} \mathrm{CH}_{2}$ \\
\hline 1417 & 1434 & 17 & 1440 & 23 & 1434 & 17 & 1458 & 41 & 1452 & 35 & 1450 & 33 & \\
\hline 1347 & 1344 & -3 & 1354 & 7 & 1345 & -2 & 1353 & 6 & 1344 & -3 & 1349 & 2 & \\
\hline 1341 & 1340 & -1 & 1348 & 7 & 1341 & 0 & 1345 & 4 & 1340 & -1 & 1323 & -18 & \\
\hline 1336 & 1339 & 3 & 1341 & 5 & 1340 & 4 & 1341 & 5 & 1338 & 2 & 1335 & -1 & \\
\hline 1308 & 1315 & 7 & 1313 & 5 & 1313 & 5 & 1315 & 7 & 1315 & 7 & 1312 & 4 & \\
\hline 1253 & 1267 & 14 & 1257 & 4 & 1278 & 25 & 1252 & -1 & 1275 & 22 & 1251 & -2 & $\rho \mathrm{CH}_{2}$ \\
\hline 1159 & 1169 & 10 & 1166 & 7 & 1167 & 8 & 1173 & 14 & 1172 & 13 & 1174 & 15 & \\
\hline 879 & 874 & -5 & 890 & 11 & 875 & -4 & 899 & 20 & 878 & -1 & 887 & 8 & \\
\hline 854 & 860 & 6 & 863 & 9 & 859 & 5 & 867 & 13 & 865 & 11 & 869 & 15 & \\
\hline 762 & 766 & 4 & 765 & 3 & 764 & 2 & 766 & 4 & 764 & 2 & 767 & 5 & \\
\hline 761 & 764 & 3 & 762 & 1 & 761 & 0 & 762 & 1 & 762 & 1 & 764 & 3 & \\
\hline 1193 & 1200 & 7 & 1182 & -11 & 1190 & -3 & 1184 & -9 & 1198 & 5 & 1188 & -5 & $v_{\text {as }} \mathrm{C}-\mathrm{NH}$ \\
\hline 1035 & 1090 & 55 & 1125 & 90 & 1092 & 57 & 1074 & 39 & 1076 & 41 & 1074 & 39 & $v_{\mathrm{s}} \mathrm{C}-\mathrm{NH}$ \\
\hline 1133 & 1152 & 19 & 1154 & 21 & 1154 & 21 & 1127 & -6 & 1127 & -6 & 1128 & -5 & $v \mathrm{C}-\mathrm{NH}_{2}$ \\
\hline 1119 & 1122 & 3 & 1099 & -20 & 1132 & 13 & 1102 & -17 & 1099 & -20 & 1100 & -19 & \\
\hline 1170 & 1185 & 15 & 1194 & 24 & 1181 & 11 & 1199 & 29 & 1193 & 23 & 1198 & 28 & $v \mathrm{C}-\mathrm{C}$ \\
\hline 1087 & 1100 & 13 & 1094 & 7 & 1103 & 16 & 1160 & 73 & 1161 & 74 & 1164 & 77 & \\
\hline 1081 & 1094 & 13 & 1083 & 2 & 1099 & 18 & 1097 & 16 & 1098 & 17 & 1103 & 22 & \\
\hline 1054 & 1053 & -1 & 1054 & 0 & 1055 & 1 & 1075 & 21 & 1058 & 4 & 1060 & 6 & \\
\hline
\end{tabular}

a In accord to Fig. 2.

b Non-scaled theoretical vibrational frequency.

c Shifts promoted on the NSpd vibrational modes upon adduct formation $\left(\Delta_{i}=\omega_{i}(\right.$ adduct $\left.)-\omega_{i}(N S p d)\right)$.

d $\nu=$ stretching, $\delta=$ scissoring, $\omega=$ wagging, $\rho=$ rocking, $t=$ twisting, $\beta=$ in-plane deformation and $\gamma=$ out-of-plane deformation; as and $\mathbf{s}$ stand for asymmetric and symmetric, respectively.

vibrational frequency calculations performed in this work. The calculated theoretical frequencies were corrected for anharmonicity and incomplete electron correlation treatment, by using the scaling factor of 0.9499 proposed by Merrick et al. [52] for the mPW1PW/6-31G* theory level. Moreover, as stated above, the account for the effects of hydrogen bonding was accounted for by considering adduct model 3 (Fig. 4). For the reasons already pointed, the LAM and TAM vibrational modes are not discriminated. 


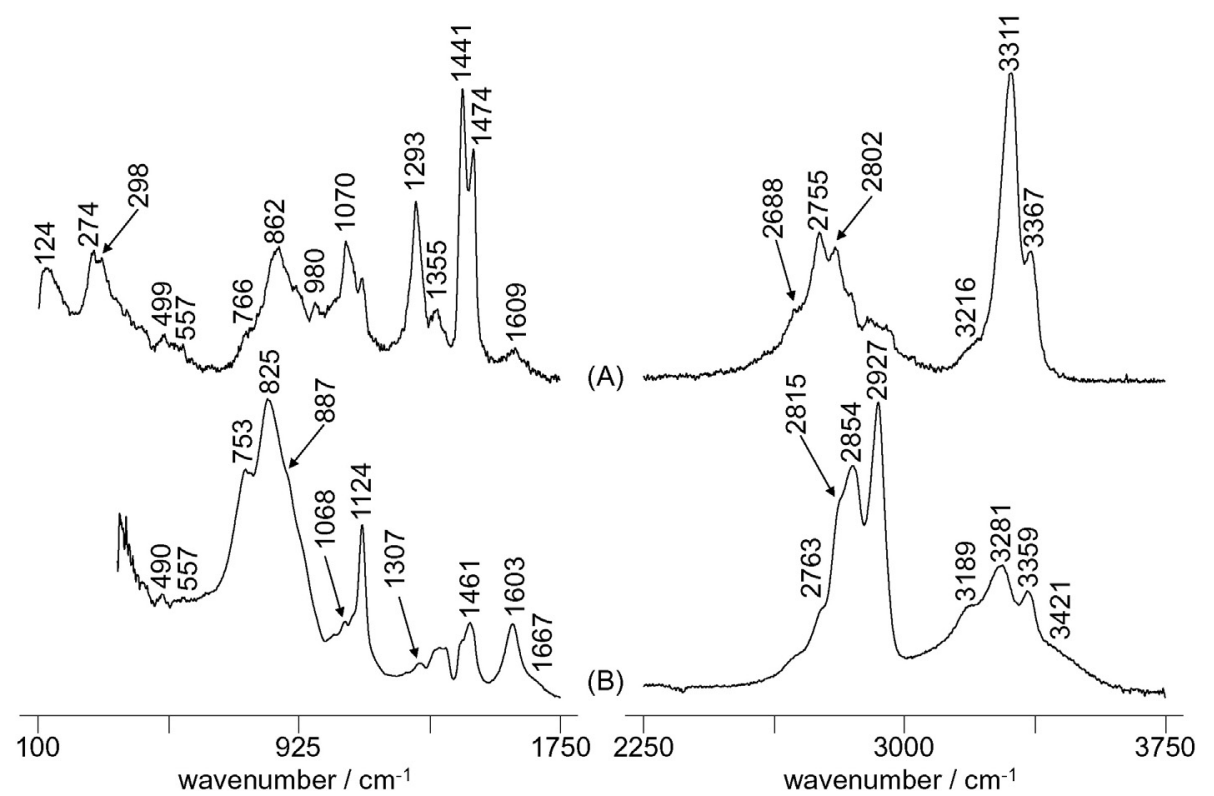

Fig. 6. Experimental vibrational spectra of NSpd in the $100-1750 \mathrm{~cm}^{-1}$ and $2250-3750 \mathrm{~cm}^{-1}$ spectral regions: (A) FT-Raman and (B) FTIR.

On the whole, the assignments performed are in good agreement with the standard assignments gathered in the literature for this kind of systems $[50,53-55]$. The $\nu_{a s} \mathrm{NH}_{2}$ are significantly blue-shifted relatively to the $v_{\mathrm{s}} \mathrm{NH}_{2}$, while the $v \mathrm{NH}$ is predicted to be mixed with these later. A shoulder observed around $3200 \mathrm{~cm}^{-1}$ has been appointed as a fingerprint of primary amines, being to an overtone of the $\delta \mathrm{NH}_{2}$ mode observed at ca. $1600 \mathrm{~cm}^{-1}[53,55]$. Therefore, it is reasonably to ascribe the shoulder observed at $3189 \mathrm{~cm}^{-1}$ in the FTIR spectrum (Fig. 6) to an overtone of the $\delta \mathrm{NH}_{2}$ mode ascribed to the spectral feature at $1603 \mathrm{~cm}^{-1}$.

Three vibrational modes that deserve a special reference are the $\mathrm{tNH}_{2}$, the $\omega \mathrm{NH}_{2}$ and the $\gamma \mathrm{NH}$ modes. Benchmark literature [50,53-55] point $\mathrm{tNH}_{2}$, the $\mathrm{\omega NH}_{2}$ and the $\gamma \mathrm{NH}$ modes as being highly mixed within the $850-700 \mathrm{~cm}^{-1}$ spectral region. The calculations performed on adduct model 3 confirm the marked mixing between the $\omega \mathrm{NH}_{2}$ and $\gamma \mathrm{NH}$ modes. These vibrational modes are referred to as giving rise to intense and broad bands $[50,53,55]$. Ascribing the spectral features observed at 825 and $862 \mathrm{~cm}^{-1}$ to a mixture of both $\omega \mathrm{NH}_{2}$ and $\gamma \mathrm{NH}$ modes is in line with the information available in the literature. With respect to the $\gamma \mathrm{NH}$ mode the data available positioning it around $740 \mathrm{~cm}^{-1}[40,41,56]$, i.e., at a significantly lower frequency than proposed herein. This is most likely related to more significant hydrogen bonding effects in NSpd, which is a triamine, compared to the monoamines regarded in those reports.

With regard to $\mathrm{tNH}_{2}$ modes, the calculations predict them at higher frequency values than the $\omega \mathrm{NH}_{2}$ and $\gamma \mathrm{NH}$ modes, turning them mixed with the skeleton elongation modes $\nu \mathrm{C}-\mathrm{C}$ and $\nu_{\mathrm{s}} \mathrm{C}-\mathrm{NH}$. These trends are also observed considering the calculations performed for the isolated NSpd molecule.

The $\mathrm{NNH}_{2}$ are, beyond doubt, the NSpd vibrational modes whose behaviour as a result of the $\mathrm{NH}_{2}$ involvement in hydrogen bonds are worth to be scrutinized. Unfortunately, the $\mathrm{\rho NH}_{2}$ modes give rise to very weak spectral features in both Raman and occur mid-IR spectra.

Calculations on the isolated NSpd molecule predict the $\mathrm{\rho NH}_{2}$ modes at $306 \mathrm{~cm}^{-1}$. Accounting for the effects of $\mathrm{N}-\mathrm{H} \cdots \mathrm{N}$ interactions leads to a significant blue-shifting of the $\mathrm{\rho NH}_{2}$ vibrations, placing them at $597 \mathrm{~cm}^{-1}$ after scaling. Such an effect has been widely reported in the literature for systems containing amine groups involved in strong intermolecular $\mathrm{N}-\mathrm{H} \cdots \mathrm{N}$ interactions $[18,28,51]$. Based on the proximity principle, we ascribe the $\mathrm{\rho NH}_{2}$ vibrational modes to the weak Raman feature around $557 \mathrm{~cm}^{-1}$. A more reliable allocation would be achieved using
INS. The INS studies performed on several di- and triamines, for example, allocate the $\mathrm{\rho NH}_{2}$ vibrational modes in the spectral region 530$550 \mathrm{~cm}^{-1}$ [17], in agreement with the assignment herein proposed.

\section{Conclusions}

The present study presents a thorough conformational study on NSpd. The most stable conformation in the condensed phase was inferred based on SCRF calculations and discussed on the light of the conformational preferences predicted for the isolated state (gas-phase). The study culminates with a full assignment of the NSpd vibrational spectra, which reassessment justifies as the prior report [23] besides being incomplete presents outstanding inconsistencies.

On the whole, it was found that the most stable conformation in the gas-phase corresponds to the $\mathrm{tGG}^{\prime} \mathrm{T}-\mathrm{TG}^{\prime} \mathrm{Gg}^{\prime}$ geometry, which is stabilized by two intramolecular $\mathrm{N}-\mathrm{H} \cdots \mathrm{N}$ hydrogen bonds. The overall stabilizing relevance of the two $\mathrm{H}$-bonds does not seem to be the same, judging by the distances $\mathrm{H} \cdots \mathrm{N}$ that characterize them. In addition, they are affected differently by the dielectric constant.

Assuming that in the condensed phase the stabilizing effect of intermolecular $\mathrm{N}-\mathrm{H} \cdots \mathrm{N}$ hydrogen bonds eventually overwhelm those of the intramolecular $\mathrm{N}-\mathrm{H} \cdots \mathrm{N}$ ones, distinct $\mathrm{NSpd}-\mathrm{NH}_{3}$ adducts were simulated in order to evaluate the relevance of considering different hydrogen bonding patterns on the overall stability and on the vibrational frequencies of NSpd. It was found that the highest CEHB is achieved by considering an adduct presenting all three amine groups engaged in two $\mathrm{H}$ bonds to distinct $\mathrm{NH}_{3}$ molecules, in all cases with an overall $\mathbf{d}-\mathbf{a}$ pattern (model 3). This result was used to infer the effects of hydrogen bonding on the relative positioning of the NSpd vibrational modes. Special attention was given to the $\nu \mathrm{NH}_{2}, \omega \mathrm{NH}_{2}, \rho \mathrm{NH}_{2}, \nu \mathrm{NH}$ and $\gamma \mathrm{NH}$ modes as they are particularly affected.

To finalize only a word of precaution, the present report clearly evidences that an accurate prediction of the vibrational frequencies requires at the outset a correct description of the molecular entity being studied. Otherwise, an incorrect description of the molecular structure and/or electronic distribution will lead to erroneous forecasts of the vibrational frequencies, culminating in inaccurate assignments.

Supplementary data to this article can be found online at http://dx. doi.org/10.1016/j.saa.2016.01.003. 
Table 3

Assignment of the vibrational spectra (Raman and FTIR) of pure liquid NSpd.

\begin{tabular}{|c|c|c|c|c|c|c|}
\hline \multicolumn{2}{|c|}{ Experimental } & \multicolumn{2}{|c|}{ Isolated NSpd } & \multicolumn{2}{|c|}{ Model 3} & \multirow[t]{2}{*}{ Assignment $^{\mathrm{C}}$} \\
\hline Raman & FTIR & $\omega^{\mathrm{a}}$ & scal. $^{\mathrm{b}}$ & $\omega^{\mathrm{a}}$ & scal. $^{\mathrm{b}}$ & \\
\hline 3367 & 3359 & 3599 & 3419 & 3554 & 3376 & $v_{\text {as }} \mathrm{NH}_{2}$ \\
\hline \multirow[t]{3}{*}{3311} & & 3599 & 3419 & 3554 & 3376 & \\
\hline & 3281 & 3509 & 3333 & 3376 & 3207 & $v_{\mathrm{s}} \mathrm{NH}_{2}$ \\
\hline & & 3509 & 3333 & 3207 & 3046 & \\
\hline \multirow[t]{2}{*}{3216} & & 3520 & 3344 & 3349 & 3181 & $\nu \mathrm{NH}$ \\
\hline & 3189 & & & & & $\mathrm{FR}\left(2 \mathrm{x} \delta \mathrm{NH}_{2}\right)$ \\
\hline \multirow[t]{4}{*}{2957} & & 3120 & 2964 & 3118 & 2962 & $v_{\mathrm{as}} \mathrm{CH}_{2}$ \\
\hline & & 3120 & 2964 & 3117 & 2961 & \\
\hline & 2927 & 3095 & 2940 & 3092 & 2937 & \\
\hline & & 3095 & 2940 & 3092 & 2937 & \\
\hline \multirow[t]{2}{*}{2900} & & 3067 & 2913 & 3062 & 2909 & $v_{\mathrm{s}} \mathrm{CH}_{2}$ \\
\hline & & 3067 & 2913 & 3061 & 2908 & \\
\hline \multirow{4}{*}{2849} & 2854 & 3077 & 2923 & 3056 & 2903 & $v_{\mathrm{as}} \mathrm{CH}_{2}$ \\
\hline & & 3074 & 2920 & 3055 & 2902 & \\
\hline & & 3040 & 2888 & 3053 & 2900 & $v_{\mathrm{s}} \mathrm{CH}_{2}$ \\
\hline & & 3040 & 2888 & 3052 & 2899 & \\
\hline 2802 & 2815 & 2952 & 2804 & 2953 & 2805 & \\
\hline 2755 & 2763 & 2947 & 2799 & 2946 & 2798 & \\
\hline \multirow[t]{2}{*}{2688} & 2689 & & & & & \\
\hline & 1667 & & & & & \\
\hline \multirow[t]{3}{*}{1609} & 1603 & 1713 & 1627 & 1746 & 1659 & $\delta \mathrm{NH}_{2}$ \\
\hline & & 1713 & 1627 & 1746 & 1659 & \\
\hline & & 1524 & 1448 & 1601 & 1521 & $\beta \mathrm{NH}$ \\
\hline \multirow[t]{2}{*}{1474} & & 1559 & 1481 & 1557 & 1479 & $\delta \mathrm{CH}_{2}$ \\
\hline & 1461 & 1547 & 1469 & 1545 & 1468 & \\
\hline \multirow[t]{7}{*}{1441} & 1440 & 1532 & 1455 & 1532 & 1455 & \\
\hline & & 1530 & 1453 & 1529 & 1452 & \\
\hline & 1389 & 1518 & 1442 & 1519 & 1443 & \\
\hline & & 1517 & 1441 & 1518 & 1442 & \\
\hline & & 1458 & 1385 & 1456 & 1383 & $\omega \mathrm{CH}_{2}$ \\
\hline & 1369 & 1418 & 1347 & 1437 & 1365 & $\mathrm{tCH}_{2}$ \\
\hline & & 1418 & 1347 & 1434 & 1362 & \\
\hline \multirow[t]{6}{*}{1355} & 1353 & 1431 & 1359 & 1427 & 1356 & $\omega \mathrm{CH}_{2}$ \\
\hline & & 1417 & 1346 & 1414 & 1343 & \\
\hline & & 1396 & 1326 & 1398 & 1328 & \\
\hline & 1307 & 1347 & 1280 & 1345 & 1278 & $\mathrm{tCH}_{2}$ \\
\hline & & 1341 & 1274 & 1341 & 1274 & \\
\hline & & 1336 & 1269 & 1340 & 1273 & \\
\hline 1293 & & 1311 & 1245 & 1314 & 1248 & $\omega \mathrm{CH}_{2}$ \\
\hline & & 1308 & 1242 & 1313 & 1247 & $\mathrm{tCH}_{2}$ \\
\hline & & 1284 & 1220 & 1291 & 1226 & $\omega \mathrm{CH}_{2}$ \\
\hline & & 1253 & 1190 & 1278 & 1214 & $\rho \mathrm{CH}_{2}$ \\
\hline 1122 & 1124 & 1193 & 1133 & 1190 & 1130 & $v_{\mathrm{as}} \mathrm{C}-\mathrm{NH}$ \\
\hline & & 1170 & 1111 & 1181 & 1122 & $\nu C-C$ \\
\hline & & 1159 & 1101 & 1167 & 1109 & $\rho \mathrm{CH}_{2}$ \\
\hline & 1095 & 1133 & 1076 & 1154 & 1096 & $\nu \mathrm{C}-\mathrm{NH}_{2}$ \\
\hline 1070 & 1068 & 1119 & 1063 & 1132 & 1075 & \\
\hline 1044 & 1037 & 1087 & 1033 & 1103 & 1048 & $\nu C-C$ \\
\hline & & 1081 & 1027 & 1099 & 1044 & $\nu C-C$ \\
\hline & & 1035 & 983 & 1092 & 1037 & $\nu_{\mathrm{s}} \mathrm{C}-\mathrm{NH}$ \\
\hline 980 & & 1055 & 1002 & 1066 & 1013 & $\mathrm{tNH}_{2}$ \\
\hline 915 & & 1054 & 1001 & 1055 & 1002 & \\
\hline & & 1035 & 983 & 1054 & 1001 & $\nu C-C$ \\
\hline 862 & & 898 & 853 & 1023 & 972 & $\omega \mathrm{NH}_{2}$ \\
\hline & & 896 & 851 & 998 & 948 & \\
\hline & 825 & 809 & 768 & 980 & 931 & $\gamma \mathrm{NH}$ \\
\hline 764 & 753 & 879 & 835 & 875 & 831 & $\rho \mathrm{CH}_{2}$ \\
\hline & & 854 & 811 & 859 & 816 & \\
\hline & & 762 & 724 & 764 & 726 & \\
\hline & & 761 & 723 & 761 & 723 & \\
\hline 557 & & $306^{\mathrm{d}}$ & & 628 & 597 & $\rho \mathrm{NH}_{2}$ \\
\hline & & $306^{\mathrm{d}}$ & & 628 & 597 & \\
\hline
\end{tabular}

a Calculated frequency value.

b Scaled values in accord to Merrick et al. [52] ( $\lambda=0.9499)$.

c $\nu=$ stretching, $\delta=$ scissoring, $\omega=$ wagging, $\rho=$ rocking, $t=$ twisting, $\beta=$ in-plane deformation and $\gamma=$ out-of-plane deformation; as and $\mathbf{s}$ stand for asymmetric and symmetric, respectively.

d Not scaled as suggested by Merrick et al. [52].

\section{Acknowledgements}

The authors acknowledge financial support from the Portuguese Foundation for Science and Technology - Unidade de Química-Física
Molecular (UID/Multi/00070/2013). TMS also acknowledges the Portuguese Foundation for Science and Technology for a PhD fellowship (SFRH/BD/46364/2008). Acknowledgements are also due to Laboratório Associado CICECO, University of Aveiro, Portugal, for the free access to the FTIR-ATR and FT-Raman spectrometers and computational facilities (G09w program).

\section{References}

[1] N. Umezawa, Y. Horai, Y. Imamura, M. Kawakubo, M. Nakahira, N. Kato, A Muramatsu, Y. Yoshikawa, K. Yoshikawa, T. Higuchi, Structurally diverse polyamines: solid-phase synthesis and interaction with DNA, Chembiochem 16 (2015) 1811-1819.

[2] W. Pan, J. Zhou, Y. Yin, H. Wen, D. Liang, Local de-condensation of double-stranded DNA in oppositely charged polyelectrolyte as induced by spermidine, Soft Matter 11 (2015) 4705-4709.

[3] T.L. Mastracci, M.A. Robertson, R.G. Mirmira, R.M. Anderson, Polyamine biosynthesis is critical for growth and differentiation of the pancreas, Scientific Reports 5 (2015), 13269.

[4] P. Icard, T. Vallantin, P. Kafara, J.M. Steyaert, L. Schwartz, H. Lincet, The decrease of citrate in tumor cells: a gauge to upgrade? Oncologie 17 (2015) 315-320.

[5] T.M. Silva, H. Cirenajwis, H.M. Wallace, S. Oredsson, L. Persson, A role for antizyme inhibitor in cell proliferation, Amino Acids 47 (2015) 1341-1352.

[6] W. Huang, J.C. Eickhoff, F. Mehraein-Ghomi, D.R. Church, G. Wilding, H.S. Basu, Expression of spermidine/spermine $\mathrm{N}$-1-acetyl transferase (SSAT) in human prostate tissues is related to prostate cancer progression and metastasis, Prostate 75 (2015) 1150-1159.

[7] L.Y. Cho, J.J. Yang, K.-P. Ko, S.H. Ma, A. Shin, B.Y. Choi, H.J. Kim, D.S. Han, K.S. Song, Y.S Kim, S.-H. Chang, H.-R. Shin, D. Kang, K.-Y. Yoo, S.K. Park, Gene polymorphisms in the ornithine decarboxylase-polyamine pathway modify gastric cancer risk by interaction with isoflavone concentrations, Gastric Cancer 18 (2015) 495-503.

[8] L. Xu, J. Long, P. Wang, K. Liu, L. Mai, Y. Guo, Association between the ornithine decarboxylase G316A polymorphism and breast, Oncol. Lett. 10 (2015) 485-491.

[9] E. Agostinelli, C. Barrero, E. Bidollari, S. Ohkubo, M. Xhani, A. Toninello, S. Merali, Can polyamines be used to combat cancer? New therapeutic approaches, Amino Acids 47 (2015) 1664.

10] B. Lorgulescu, S. Patel, J. Louro, C. Andrade, A. Sanchez, D. Pearse, 182Acute putrescine supplementation with Schwann cell transplantation improves sensory and serotonergic axon growth and functional recovery in spinal cord injury, Neurosurgery 62 (2015) 226-227.

[11] N. Han, L. Yu, Z. Song, L. Luo, Y. Wu, Agmatine protects Muller cells from highconcentration glucose-induced cell damage via N-methyl-D-aspartic acid receptor inhibition, Mol. Med. Rep. 12 (2015) 1098-1106.

[12] B. Rosenberg, L.V. Camp, T. Krigas, Inhibition of cell division in Escherichia coli by electrolysis products from a platinum electrode, Nature 205 (1965) 698-699.

[13] B. Rosenberg, L. Vancamp, J.E. Trosko, V.H. Mansour, Platinum compounds - a new class of potent antitumour agents, Nature 222 (1969) 385-387.

[14] B. Rosenberg, Some biological effects of platinum compounds - new agents for the control of tumours, Platin. Met. Rev. 15 (1971) 42-51.

[15] M.J. Cleare, J.D. Hoeschele, Anti-tumour platinum compounds - relationship between structure and activity, Platin. Met. Rev. 17 (1973) 2-13.

[16] K. Wang, E. Gao, Recent advances in multinuclear complexes as potential anticancer and DNA binding agents, Anti Cancer Agents Med. Chem. 14 (2014) 147-169.

[17] M.P.M. Marques, L.A.E. Batista de Carvalho, J. Tomkinson, Study of biogenic and $\alpha, \omega-$ polyamines by combined inelastic neutron scattering and Raman spectroscopies and by ab initio molecular orbital calculations, J. Phys. Chem. A 106 (2002) 2473-2482.

[18] A.M. Amado, J.C. Otero, M.P.M. Marques, L.A.E. Batista de Carvalho, Spectroscopic and theoretical studies on solid 1,2-ethylenediamine dihydrochloride salt ChemPhysChem 5 (2004) 1837-1847.

[19] L.A.E. Batista de Carvalho, M.P.M. Marques, J. Tomkinson, Transverse acoustic modes of biogenic and $\alpha, \omega$-polyamines: a study by inelastic neutron scattering and Raman spectroscopies coupled to DFT calculations, J. Phys. Chem. A 110 (2006) 12947-12954.

[20] A.M. Amado, S.M. Fiuza, M.P.M. Marques, L.A.E. Batista de Carvalho, Conformational and vibrational study of platinum(II) anticancer drugs: cisdiamminedichloroplatinum(II) as a case study, J. Chem. Phys. 127 (2007), 185104.

[21] M.P.M. Marques, L.A.E. Batista de Carvalho, Vibrational spectroscopy studies on linear polyamines, Biochem. Soc. Trans. 35 (2007) 374-380.

[22] S.M. Fiuza, A.M. Amado, H.F. dos Santos, M.P.M. Marques, L.A.E. Batista de Carvalho, Conformational and vibrational study of cis-diamminedichloropalladium(II), Phys. Chem. Chem. Phys. 12 (2010) 14309-14321.

[23] T.M. Silva, S. Oredsson, L. Persson, P. Woster, M.P.M. Marques, Novel Pt(II) and Pd(II) complexes with polyamine analogues: synthesis and vibrational analysis, J. Inorg. Biochem. 108 (2012) 1-7.

[24] A.L.M. Batista de Carvalho, S.M. Fiuza, J. Tomkinson, L.A.E. Batista de Carvalho, M.P. Marques, Pt(II) complexes with linear diamines - part I: vibrational study of Ptdiaminopropane, Spectroscopy 27 (2012), 206297 (206211 pages).

[25] S. Padrão, S.M. Fiuza, A.M. Amado, A.M. Amorim da Costa, L.A.E. Batista de Carvalho, Validation of the mPW1PW quantum chemical calculations for the vibrational study of organic molecules - re-assignment of the isopropylamine vibrational spectra, J. Phys. Org. Chem. 24 (2012) 110-121. 
[26] A.M. Amado, S.M. Fiuza, L.A.E. Batista de Carvalho, P.J.A. Ribeiro-Claro, On the effects of changing Gaussian program version and SCRF defining parameters: isopropylamine as a case study, Bull. Chem. Soc. Jpn. 85 (2012) 962-975.

[27] M.P.M. Marques, R. Valero, S.F. Parker, J. Tomkinson, L.A.E. Batista de Carvalho, Polymorphism in cisplatin anticancer drug, J. Phys. Chem. B 117 (2013) 6421-6429.

[28] A.M. Amado, S.M. Fiuza, L.A.E. Batista de Carvalho, P.J.A. Ribeiro-Claro, On the relevance of considering the intermolecular interactions on the prediction of the vibrational spectra of isopropylamine, J. Chem. (2013), 682514

[29] S.M. Fiuza, A.M. Amado, S.F. Parker, M.P.M. Marques, L.A.E. Batista de Carvalho, Conformational insights and vibrational study of a promising anticancer agent: the role of the ligand in Pd(II)-amine complexes, New J. Chem. 39 (2015) 6274-6283.

[30] M.P.M. Marques, D. Gianolio, G. Cibin, J. Tomkinson, S.F. Parker, R. Valero, R.P. Lopes, L.A.E. Batista de Carvalho, A molecular view of cisplatin's mode of action: interplay with DNA bases and acquired resistance, Phys. Chem. Chem. Phys. 17 (2015) 5155-5171.

[31] T.M. Silva, S. Andersson, S.K. Sukumaran, M.P. Marques, L. Persson, S. Oredsson, Norspermidine and novel Pd(II) and Pt(II) polynuclear complexes of norspermidine as potential antineoplastic agents against breast cancer, PLoS One 8 (2013), e55651.

[32] M.J. Frisch, G.W. Trucks, H.B. Schlegel, G.E. Scuseria, M.A. Robb, J.R. Cheeseman, G. Scalmani, V. Barone, B. Mennucci, G.A. Petersson, H. Nakatsuji, M. Caricato, X. Li, H.P. Hratchian, A.F. Izmaylov, J. Bloino, G. Zheng, J.L. Sonnenberg, M. Hada, M. Ehara, K. Toyota, R. Fukuda, J. Hasegawa, M. Ishida, T. Nakajima, Y. Honda, O. Kitao, H. Nakai, T. Vreven, J.A. Montgomery Jr., J.E. Peralta, F. Ogliaro, M. Bearpark J.J. Heyd, E. Brothers, K.N. Kudin, V.N. Staroverov, R. Kobayashi, J. Normand, K. Raghavachari, A. Rendell, J.C. Burant, S.S. Iyengar, J. Tomasi, M. Cossi, N. Rega, J.M Millam, M. Klene, J.E. Knox, J.B. Cross, V. Bakken, C. Adamo, J. Jaramillo, R. Gomperts, R.E. Stratmann, O. Yazyev, A.J. Austin, R. Cammi, C. Pomelli, J.W. Ochterski, R.L. Martin, K. Morokuma, V.G. Zakrzewski, G.A. Voth, P. Salvador, J.J. Dannenberg, S. Dapprich, A.D. Daniels, O. Farkas, J.B. Foresman, J.V. Ortiz, J. Cioslowski, D.J. Fox, Gaussian 09, Revision A.02, Gaussian, Inc., Wallingford CT, 2009.

[33] S.M. Fiuza, T.M. Silva, M.P.M. Marques, L.A.E.B. de Carvalho, A.M. Amado, On the correction of calculated vibrational frequencies for the effects of the counterions $\alpha, \omega$ diamine dihydrochlorides, J. Mol. Model. C7 - 266 (21) (2015) 1-13.

[34] J. Richardi, H. Krienke, P.H. Fries, Dielectric constants of liquid formamide, Nmethylformamide and dimethylformamide via molecular Ornstein-Zernike theory, Chem. Phys. Lett. 273 (1997) 115-121.

[35] A.E. Reed, F. Weinhold, Natural localized molecular-orbitals, J. Chem. Phys. 83 (1985) 1736-1740

[36] A.E. Reed, R.B. Weinstock, F. Weinhold, Natural-population analysis, J. Chem. Phys. 83 (1985) 735-746.

[37] A.E. Reed, L.A. Curtiss, F. Weinhold, Intermolecular interactions from a natural bond orbital, donor-acceptor viewpoint, Chem. Rev. 88 (1988) 899-926.

[38] L.A.E Batista de Carvalho, A.M.A da Costa, M.L Duarte, J.J.C. Teixeira-Dias, Conformational studies of n-propylamine by combined ab initio MO calculations and Raman spectroscopy, Spectrochim. Acta A44 (1988) 723-732.
[39] L.A.E. Batista de Carvalho, L.E. Lourenco, M.P.M. Marques, Conformational study of 1,2-diaminoethane by combined ab initio MO calculations and Raman spectroscopy, J. Mol. Struct. 482\&483 (1999) 639-646.

[40] L.A.E. Batista de Carvalho, J.J.C. Teixeira-Dias, Raman spectra, conformational stability and normal coordinate analysis of ethylmethylamine, J. Raman Spectrosc. 26 (1995) 653-661.

[41] L.A.E. Batista de Carvalho, J.J.C. Teixeira-Dias, R. Fausto, A molecular mechanics force field for conformational analysis of aliphatic acyclic amines, Struct. Chem. 1 (1990) 533-542.

[42] L.A.E. Batista de Carvalho, J.J.C. Teixeira-Dias, Conformational analysis of dimethylethylamine: an ab initio MO study and comparison with ethylamine and ethylmethylamine, J. Mol. Struct. (THEOCHEM) 282 (1993) 211-221.

[43] P.L. Huyskens, Factors governing influence of a 1st hydrogen-bond on formation of a 2nd one by same molecule or ion, J. Am. Chem. Soc. 99 (1977) 2578-2582.

[44] I.A.W. Filot, A.R.A. Palmans, P.A.J. Hilbers, R.A. van Santen, E.A. Pidko, T.F.A. de Greef, Understanding cooperativity in hydrogen-bond-induced supramolecular polymerization: a density functional theory study, J. Phys. Chem. B 114 (2010) 13667-13674.

[45] E.M. Cabaleiro-Lago, M.A. Ríos, Ab initio study of interactions in methylamine clusters. The significance of cooperative effects, J. Chem. Phys. 112 (2000) 2155-2163.

[46] E.M. Cabaleiro-Lago, M.A. Ríos, An ab initio study of the interaction in dimethylamine dimer and trimer, J. Chem. Phys. 113 (2000) 9523-9531.

[47] M.M. Nolasco, A.M. Amado, P.J.A. Ribeiro-Claro, Effect of hydrogen bonding in the vibrational spectra of trans-cinnamic acid, J. Raman Spectrosc. 40 (2009) 394-400.

[48] G.A. Giffin, S. Boesch, D.N. Bopege, D.R. Powell, R.A. Wheeler, R. Frech, Vibrational spectroscopy of secondary amine salts: 1 . Assignment of $\mathrm{NH}_{2}^{+}$stretching frequencies in crystalline phases, J. Phys. Chem. B 113 (2009) 15914-15920.

[49] R. Dennington, T. Keith, J. Millam, GaussView, Version 5, Gaussian, Inc., Shawnee Mission KS, 2009.

[50] L.J. Bellamy, The Infrared Spectra of Complex Molecules, third ed. Chapman and Hall Ltd., London, 1975.

[51] L. Choongkeun, P. Sun-Kyung, M. Kyung-Chul, K. Yunsoo, L. Nam-Soo, Vibrational analysis and intermolecular hydrogen bonding of azodicarbonamide in the pentamer cluster, Bull. Kor. Chem. Soc. 29 (2008) 1951-1959.

[52] J.P. Merrick, D. Moran, L. Radom, An evaluation of harmonic vibrational frequency scale factors, J. Phys. Chem. A 111 (2007) 11683-11700.

[53] N.B. Coulthup, L.H. Daly, S.E. Wiberley, Introduction to Infrared and Raman Spectroscopy, third ed. Academic Press, INC, San Diego, 1990.

[54] B. Stuart, Biological Applications of Infrared Spectroscopy, third ed. John Wiley \& Sons, Ltd, West Sussex, 1997.

[55] H. Günzler, H.-U. Gremlich, IR Spectroscopy - an Introduction, first ed. Weinheim, Wiley-VCH Verlag GmbH, 2002.

[56] L.A.E. Batista de Carvalho, A.M.A. Da Costa, J.J.C. Teixeira-Dias, E.F.G. Barbosa, I.M.S. Lampreia, Temperature-dependent intensities of Raman bands of di-n-butylamine, J. Raman Spectrosc. 18 (1987) 115-118. 